\title{
Multispectral imaging of cortical vascular and hemodynamic responses to a shock wave: observation of spreading depolarization and oxygen supply-demand mismatch
}

Satoko Kawauchi

Wataru Okuda

Hiroshi Nawashiro

Shunichi Sato

Izumi Nishidate 


\title{
Multispectral imaging of cortical vascular and hemodynamic responses to a shock wave: observation of spreading depolarization and oxygen supply-demand mismatch
}

\author{
Satoko Kawauchi, ${ }^{a, *, \dagger}$ Wataru Okuda, ${ }^{b, \dagger}$ Hiroshi Nawashiro, ${ }^{c}$ Shunichi Sato, ${ }^{a}$ and Izumi Nishidate ${ }^{b}$ \\ ${ }^{a}$ National Defense Medical College Research Institute, Division of Bioinformation and Therapeutic Systems, Tokorozawa, Japan \\ ${ }^{\mathrm{b}}$ Tokyo University of Agriculture and Technology, Graduate School of Bio-Applications and Systems Engineering, Tokyo, Japan \\ ${ }^{c}$ Tokorozawa Central Hospital, Division of Neurosurgery, Tokorozawa, Japan
}

\begin{abstract}
Blast-induced traumatic brain injury has been a recent major concern in neurotraumatology. However, its pathophysiology and mechanism are not understood partly due to insufficient information on the brain pathophysiology during/immediately after shock wave exposure. We transcranially applied a laserinduced shock wave (LISW, $\sim 19 \mathrm{~Pa} \cdot \mathrm{s}$ ) to the left frontal region in a rat and performed multispectral imaging of the ipsilateral cortex through a cranial window $(n=4)$. For the spectral data obtained, we conducted multiple regression analysis aided by Monte Carlo simulation to evaluate vascular diameters, regional hemoglobin concentration $\left(\mathrm{rC}_{\mathrm{Hb}}\right)$, tissue oxygen saturation $\left(\mathrm{StO}_{2}\right)$, oxygen extraction fraction, and light-scattering signals as a signature of cortical spreading depolarization (CSD). Immediately after LISW exposure, $\mathrm{rC}_{\mathrm{Hb}}$ and $\mathrm{StO} \mathrm{O}_{2}$ were significantly decreased with distinct venular constriction. CSD was then generated and was accompanied by distinct hyperemia/hyperoxemia. This was followed by oligemia with arteriolar constriction, but it soon recovered (within 20 min). However, severe hypoxemia was persistently observed during the post-CSD period $(\sim 1 \mathrm{~h})$. These observations indicate that inadequate oxygen supply and/or excessive oxygen consumption continued even after blood supply was restored in the cortex. Such a hypoxemic state and/or a hypermetabolic state might be associated with brain damage caused by a shock wave. $\odot$ The Authors. Published by SPIE under a Creative Commons Attribution 4.0 Unported License. Distribution or reproduction of this work in whole or in part requires full attribution of the original publication, including its DOI. [DOI: 10.1117/1.JBO.24.3.035005]
\end{abstract}

Keywords: blast-induced mild traumatic brain injury; multispectral imaging; diffuse reflectance; cortical spreading depolarization; hemodynamics; light scattering.

Paper 180591R received Oct. 19, 2018; accepted for publication Feb. 12, 2019; published online Mar. 8, 2019.

\section{Introduction}

In recent years, the risk of military personnel and civilians suffering from blast-induced traumatic brain injury (bTBI) has been increasing due to frequent attacks using improvised explosive devices. $^{1-4}$ The majority of the patients $(>90 \%)$ have been categorized as having mild to moderate TBI; most of them do not show any abnormality by conventional structural brain imaging, such as computed tomography. However, many of the patients suffer from higher-order brain dysfunction as well as other chronic symptoms, such as headaches, photophobia, and insomnia, which considerably decrease their quality of life. ${ }^{1-4}$ Despite extensive studies, the pathophysiology and mechanisms of such bTBI have not been fully elucidated. This is largely due to, in addition to the complex interactions of the brain with a shock wave, the lack of information on physiological, structural, and functional changes in the brain during and immediately after shock wave exposure in vivo. Since initial events caused by a shock wave can trigger cascading processes leading to pathological consequences in the chronic phase, real-time observation of the cerebral responses to a shock wave is crucial for

\footnotetext{
*Address all correspondence to Satoko Kawauchi, E-mail: skawauch@ndmc .ac.jp

TThese authors contributed equally to this work.
}

understanding the mechanism of bTBI. However, real-time monitoring and assessment of the brain exposed to a shock wave is generally difficult, since sensing or detecting systems can be considerably affected by an experimental blast or shock wave. Here, optical technologies can play important roles.

We have been using a laser-induced shock wave (LISW) to investigate the pathophysiology and mechanism of bTBI. ${ }^{5-10}$ The advantages of the use of an LISW for bTBI research include its safety, ease in handling, and ability to precisely control the shock wave energy and size. In addition, the confined nature of the shock wave energy of an LISW enables site-specific or targeted application to animals, which is useful because blast injuries resulting from systemic blast exposure are often too complex to analyze or understand the mechanism of injuries. ${ }^{1-13}$ Furthermore, sensors can be safely placed in the vicinity of the site of LISW exposure, enabling real-time monitoring of the brain pathophysiology. In our previous study, we performed transcranial real-time diagnosis of the rat brain exposed to an LISW by using optical fiber-based diffuse reflectance spectroscopy (DRS). ${ }^{5,14}$ We observed that, immediately after LISW application, cortical spreading depolarization (CSD) was generated at the site of LISW application and propagated over the entire ipsilateral cortex. This was accompanied by distinct hyperemia/hyperoxemia, but after CSD propagation, long-lasting hypoxemia/oligemia was observed for up to $\sim 3 \mathrm{~h}$. CSD is a wave of near-complete neuronal and glial 
depolarization associated with massive transmembrane ionic and water movements, therefore imposing a considerable metabolic workload on the tissue for restoration of imbalanced ions. Thus, CSD has received much attention to understand the mechanism and symptoms of various brain diseases and injury. ${ }^{15-17}$ To the authors' best knowledge, however, there has been no report on the occurrence of CSD in bTBI animal models.

Importantly, it has been reported that the consequences of CSD vary depending on the baseline metabolic and hemodynamic states in the tissue. In addition, since CSD is a neurovascular event, bidirectional interactions between the parenchymal tissue and cerebral vasculature during and after CSD are crucial for understanding the pathological consequences of CSD in its disease. ${ }^{15,16}$ However, detailed characteristics of shock wave-induced CSD are not elucidated. In this study, we performed multispectral imaging of the cortex of the rat brain that was transcranially exposed to an LISW and quantified two-dimensional cerebral hemodynamics and tissue scattering parameters using multiple regression analysis aided by Monte Carlo simulation for the spectral data obtained. ${ }^{18,19}$ We assessed morphological changes of vessels and visualized distributions of regional hemoglobin concentration $\left(\mathrm{rC}_{\mathrm{Hb}}\right)$ and tissue oxygen saturation $\left(\mathrm{StO}_{2}\right)$ for three time regimes: (i) just after LISW application (before the start of CSD), (ii) during CSD propagation, and (iii) after CSD propagation. Importantly, vascular type-dependent behaviors were observed, and the results were therefore analyzed for each vascular type (arteriolar, venular, and capillaries). Oxygen extraction fraction (OEF) was also evaluated as a clinically relevant parameter related to cerebral oxygen metabolism. To the authors' best knowledge, there is no report on such detailed spatiotemporal responses of the brain exposed to a shock wave in such super acute phases. On the basis of all the results obtained, we discuss possible mechanisms of brain tissue alteration after exposure to a shock wave.

\section{Materials and Methods}

All requests for animals and intended procedures in the present study were approved by the Ethics Committee of Animal Care and Experimentation, National Defense Medical College, Japan (permission numbers: 13024, 16036). All animal experiments were performed under anesthesia, as described later, and all efforts were made to minimize suffering.

\subsection{Generation and Characteristics of a Laser-Induced Shock Wave}

Figure 1(a) shows the method for generation of an LISW. A laser target, which was a light-absorbing material (0.5-mm-thick natural black rubber disk) on which an optically transparent material (1.0-mm-thick polyethylene terephthalate sheet) was adhered with adhesive, was placed on the tissue. The laser target was irradiated with a high-intensity laser pulse from a 532-nm Q-switched Nd:YAG laser [pulse width, 6-ns full-width at halfmaximum (FWHM); Brilliant b, Quantel, Les Ulis Cedex, France). The laser pulse was absorbed by the black rubber to induce plasma and its expansion generated a shock wave (LISW). We previously observed that an LISW generated at a laser fluence of $1.25 \mathrm{~J} / \mathrm{cm}^{2}$ with a spot diameter of $4 \mathrm{~mm}$ (peak pressure: $\sim 104 \mathrm{MPa}$, impulse: $\sim 19 \mathrm{~Pa} \cdot \mathrm{s}$, positive pulse duration: $\sim 0.8 \mu \mathrm{s}$ ) caused CSD in all of the five rats examined. ${ }^{5}$ In this condition, transcranial application of a single LISW to (a)

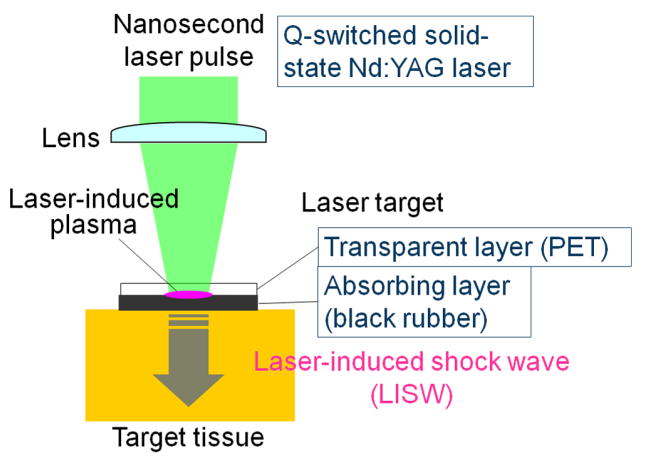

(b)

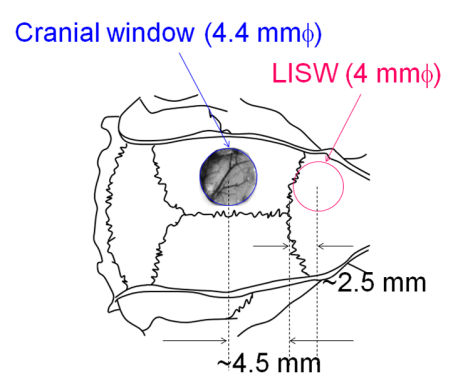

(c)

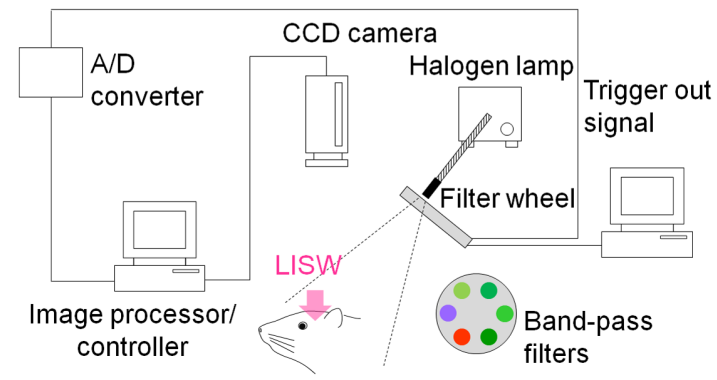

Fig. 1 Schematics showing (a) the method for generation of a LISW, (b) positions of LISW application and the cranial window for imaging, and (c) experimental setup for multispectral imaging of the rat brain.

a rat brain caused either no or limited hemorrhage in the cortical surface. On the basis of the histopathological analysis, we also confirmed that there was neither thermal damage nor mechanical damage (contusion) in the cortex at the same condition (data not shown). Thus, this condition can be regarded as mild or mild-to-moderate injury and was used in the present study. The peak pressure of an LISW is 2 to 3 orders of magnitude higher than that of medically relevant actual explosion shock waves, while the positive pressure duration of an LISW is 2 to 3 orders of magnitude shorter. As a result, the impulse (the time-integrated positive pressure component), which is known to be one of the most important parameters to determine tissue damage, is in the same order as that of relevant actual explosion shock waves. ${ }^{20}$ Thus, we assume that the condition we used is valid to investigate the brain pathophysiology associated with bTBI in rats.

\subsection{Surgical Preparation and LISW Application}

Male Sprague-Dawley rats weighing 300 to $400 \mathrm{~g}$ (10 to 12 weeks of age, $n=4$, Japan SLC, Inc., Shizuoka, Japan) were anesthetized with an intraperitoneal injection of pentobarbital sodium (50 mg/kg bolus and $\sim 15 \mathrm{mg} / \mathrm{kg} / \mathrm{h}$ maintenance) 
and placed in a stereotactic frame. After shaving the head, the scalp was incised at the midline and the parietal bone was exposed. During experiments, adequacy of anesthesia was checked by the absence of a response to tail pinch. For multispectral imaging, a cranial window with a diameter of $\sim 4.5 \mathrm{~mm}$ was prepared with the dura intact in the left parietal bone with a trephine (Roboz Surgical Instrument. Co., Inc., Gaithersburg, Maryland) under a surgical microscope (OPMI Pico/S100, Carl Zeiss, Germany). A disk of transparent polymethyl methacrylate with a diameter of $4.4 \mathrm{~mm}$ and a thickness of $\sim 0.5 \mathrm{~mm}$ was inserted within the window and sealed with dental cement. Figure 1(b) shows a schematic illustrating positions of the cranial window and the site of LISW application. The distance between the center of the LISW and the center of the cranial window was $\sim 7 \mathrm{~mm}$. After window preparation, the rat was moved to the position for imaging and placed in another stereotactic frame. The body temperature was kept constant at $37.0^{\circ} \mathrm{C} \pm 0.5^{\circ} \mathrm{C}$ by using a temperature-controlled body mat, and arterial oxygen saturation $\left(\mathrm{SpO}_{2}\right)$ was continuously monitored at the hindlimb with a pulse oximeter $(8600 \mathrm{~V}$, Nonin Medical, Inc., Plymouth, Minnesota).

\subsection{Multispectral Imaging}

Through the window described above, we performed multispectral imaging of the cortex to observe CSD, morphology of vessels (changes in diameters of cortical surface vessels), $\mathrm{rC}_{\mathrm{Hb}}$, and $\mathrm{StO}_{2}$ before, during, and after LISW application. Figure 1(c) shows a diagram of the experimental setup. The parietal region was illuminated with the light from a halogen lamp (HL 100E, HOYA-Schott, Tokyo, Japan); the wavelength of the light was changed sequentially using a rotating filter wheel (FW102C, Thorlabs, Newton, New Jersey) with six bandpass filters. The center wavelengths of the filters were 520, 540, 560, 580, 600 , and $800 \mathrm{~nm}$ and their bandwidths were $10 \mathrm{~nm}$ FWHM (520 to $600 \mathrm{~nm})$ or $40 \mathrm{~nm}$ FWHM $(800 \mathrm{~nm})$; the diameters of the filters were $\sim 25 \mathrm{~mm}$ (Thorlabs). Diffusely reflected light from the cortex was captured with a CCD (12 bit, $1034 \times 779$ pixels, 1/30 s/frame, scA1000-30fm, Basler AG, Ahrensburg, Germany) equipped with a unifocal lens ( $f=50 \mathrm{~mm}$, M118FM50, Tamron Co., Ltd., Saitama, Japan). The filter wheel was rotated every $1.5 \mathrm{~s}$ using accessory software (Thorlabs), and image acquisitions were synchronized with the filter rotations using an output signal from the filter wheel and LabVIEW software (National Instruments, Austin, Texas), the image acquisition rate being 1 image per $1.5 \mathrm{~s}$ at each wavelength. Since images at 5 of the 6 wavelengths were used for quantitative analyses as described later, the actual imaging rate was 1 image per $7.5 \mathrm{~s}$. A laser target was placed on the skull in the frontal region and held with forceps; ultrasound gel was applied between the bottom of the target (rubber) and the skull surface for acoustic impedance matching. Baseline images were acquired at least for $2 \mathrm{~min}$, and the target was then irradiated with a single laser pulse to produce an LISW, and imaging was continued for $\sim 60 \mathrm{~min}$. After imaging, a certified diffuse reflectance standard plate (SRS-99-020, Labsphere, Inc., North Sutton, New Hampshire) was placed at the same position and its image was acquired under the same imaging conditions. All multispectral images acquired for the cortex were divided by images acquired for the reflectance standard at the corresponding wavelengths, which were used as diffuse reflectance $r(\lambda)$ images to calculate optical and physiological parameters, as described below.

\subsection{Estimation of Cerebral Absorption (Hemodynamics) and Scattering Parameters}

We performed multiple regression analysis with Monte Carlo simulation to map the reduced scattering coefficient, which was used as an optical marker for $\mathrm{CSD},{ }^{5}$ and absorption coefficient as well as $\mathrm{rC}_{\mathrm{Hb}}$ and $\mathrm{StO}_{2}$, using MATLAB software (Mathworks, Natick, Massachusetts). Images at 520, 540, 560,580 , and $600 \mathrm{~nm}$ were used for assessing the reduced scattering coefficient and concentrations of oxygenated hemoglobin $\left(C_{\mathrm{HbO}}\right)$ and deoxygenated hemoglobin $\left(C_{\mathrm{HbR}}\right)$, while images at $800 \mathrm{~nm}$ were used to determine the propagation velocity of CSD, as described below. The method is basically the same as that used in our previous study. ${ }^{19,21}$ Figure 2 shows the flow diagram of the method. Absorbance spectrum $A(\lambda)$ was calculated from diffuse reflectance $r(\lambda)$ based on the following equation:

$\mathrm{A}(\lambda)=-\log _{10} r(\lambda)$

where $r(\lambda)$ corresponds to the diffuse reflectance spectrum normalized by the incident light spectrum. Because attenuation due to light scattering can be treated as pseudochromophore, ${ }^{22,23}$ the absorbance spectrum $A(\lambda)$ can be approximated as the sum of attenuations due to absorption and scattering in the brain as follows:

$$
\begin{aligned}
A(\lambda)= & \mathrm{C}_{\mathrm{HbO}} l\left(\lambda, \mathrm{C}_{\mathrm{HbO}}, \mathrm{C}_{\mathrm{HbR}}, \mu_{s}^{\prime}\right) \varepsilon_{\mathrm{HbO}}(\lambda) \\
& +\mathrm{C}_{\mathrm{HbR}} l\left(\lambda, \mathrm{C}_{\mathrm{HbO}}, \mathrm{C}_{\mathrm{HbR}}, \mu_{s}^{\prime}\right) \varepsilon_{\mathrm{HbR}}(\lambda)+D\left(\lambda, \mu_{s}^{\prime}\right),
\end{aligned}
$$

where $\mathrm{C}$ is the concentration, $l$ is the mean path length, $\varepsilon$ is the molar extinction coefficient, and $D\left(\lambda, \mu_{\mathrm{s}}^{\prime}\right)$ indicates attenuation due to light scattering in the brain. The subscripts $\mathrm{HbO}$ and $\mathrm{HbR}$ denote oxygenated hemoglobin and deoxygenated hemoglobin, respectively. The absorption coefficient of the cortical tissue was assumed to depend only on $C_{\mathrm{HbO}}$ and $C_{\mathrm{HbR}}$ as follows:

$\mu_{a}(\lambda)=C \varepsilon(\lambda)=\mathrm{C}_{\mathrm{HbO}} \varepsilon_{\mathrm{HbO}}(\lambda)+\mathrm{C}_{\mathrm{HbR}} \varepsilon_{\mathrm{HbR}}(\lambda)$.

The total hemoglobin concentration $C_{\mathrm{HbT}}$, also referred to as $C_{\mathrm{Hb}}$, is defined as the sum of $C_{\mathrm{HbO}}$ and $C_{\mathrm{HbR}}$ as follows:

$\mathrm{C}_{\mathrm{HbT}}=\mathrm{C}_{\mathrm{HbO}}+\mathrm{C}_{\mathrm{HbR}}$.

The tissue oxygen saturation is determined as follows:

$\mathrm{StO}_{2}=\frac{\mathrm{C}_{\mathrm{HbO}}}{\mathrm{C}_{\mathrm{HbO}}+\mathrm{C}_{\mathrm{HbR}}} \times 100$.

The reduced scattering coefficient of the brain tissue was assumed to be in the following form: ${ }^{24,25}$

$\mu_{s}^{\prime}(\lambda)=a \lambda^{-b}$

where the coefficient $a$ represents the scattering amplitude and $b$ is the scattering power being constant at $1.38 .^{26}$ By using $A(\lambda)$ as a response variable and known extinction coefficients of oxygenated hemoglobin $\varepsilon_{\mathrm{HbO}}(\lambda)$ and deoxygenated hemoglobin $\varepsilon_{\mathrm{HbR}}(\lambda)$ as predictor variables, the multiple regression analysis based on the modified Lambert-Beer law (MRA1) can be applied to Eq. (2) as follows: 
(a)

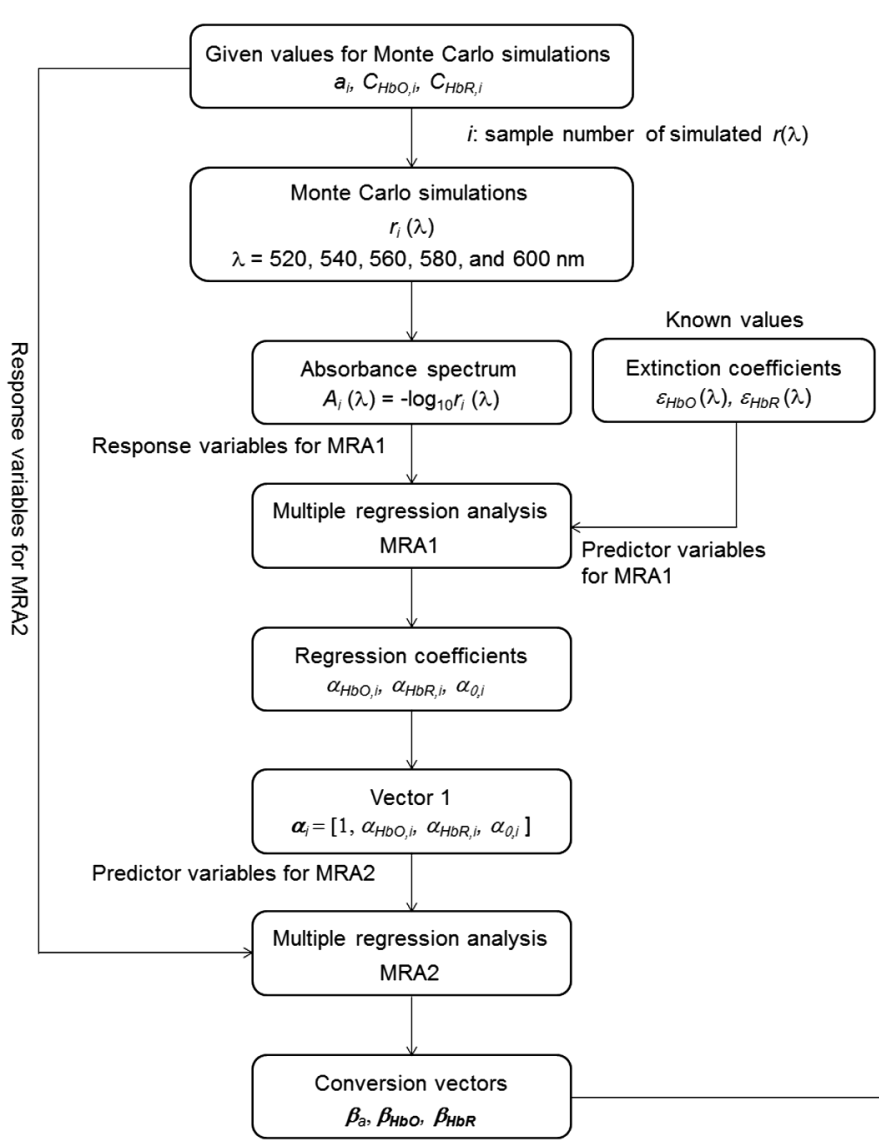

(b) Main process

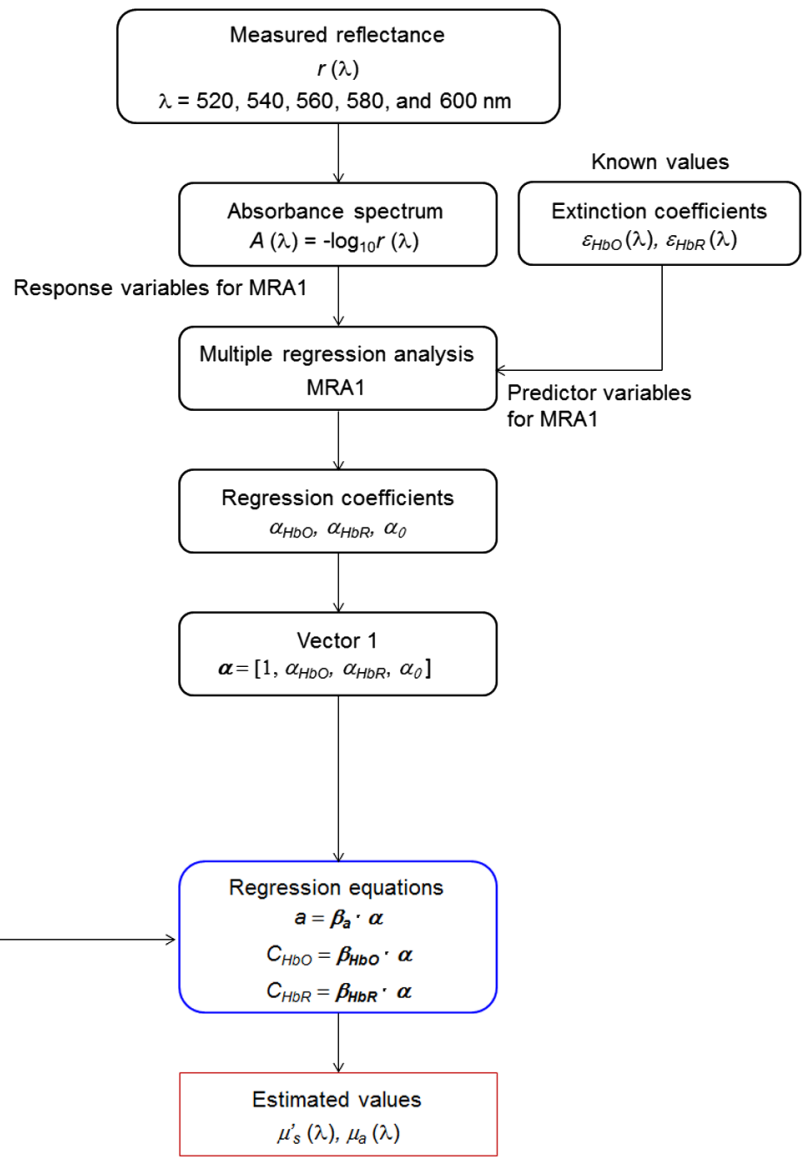

Fig. 2 Flow diagram of the process for estimating the concentration of oxygenated hemoglobin $\left(C_{\mathrm{HbO}}\right)$, the concentration of deoxygenated hemoglobin $\left(C_{\mathrm{HbR}}\right)$, and scattering amplitude $a$. (a) Preparation work for determination of the regression equations and (b) main process to estimate $C_{\mathrm{HbO}}$ and $C_{\mathrm{HbR}}$ from the measured reflectance spectrum $r(\lambda)$.

$\mathrm{A}(\lambda)=\alpha_{\mathrm{HbO}} \varepsilon_{\mathrm{HbO}}(\lambda)+\alpha_{\mathrm{HbR}} \varepsilon_{\mathrm{HbR}}(\lambda)+\alpha_{0}$,

where $\alpha_{\mathrm{HbO}}, \alpha_{\mathrm{HbR}}$, and $\alpha_{0}$ are the regression coefficients. The regression coefficients $\alpha_{\mathrm{HbO}}$ and $\alpha_{\mathrm{HbR}}$ describe the degree of contribution of each extinction coefficient to $A(\lambda)$ and are closely related to the concentrations $C_{\mathrm{HbO}}$ and $C_{\mathrm{HbR}}$, respectively. The regression coefficient $\alpha_{0}$ is expressed as follows:

$\alpha_{0}(\lambda)=\bar{A}-\bar{\varepsilon}_{\mathrm{HbO}} \alpha_{\mathrm{HbO}}-\bar{\varepsilon}_{\mathrm{HbR}} \alpha_{\mathrm{HbR}}$,

where $\bar{A}, \bar{\varepsilon}_{\mathrm{HbO}}$, and $\bar{\varepsilon}_{\mathrm{HbR}}$ are the averages of $A, \varepsilon_{\mathrm{HbO}}$, and $\varepsilon_{\mathrm{HbR}}$ over the wavelength range, respectively. $\alpha_{0}$ represents the bias component of $A(\lambda)$. Thus, $\alpha_{0}$ describe the degree of contribution of the attenuation due to light scattering in the brain to the absorbance spectrum $A(\lambda)$ and hence, it is related to the coefficient $a$ in Eq. (6). At the same time, $\alpha_{0}$ is also affected by absorption coefficient of the brain, since $A(\lambda)$ is generally a function of the tissue absorption coefficient and reduced scattering coefficient.
As described above, the regression coefficients $\alpha_{\mathrm{HbO}}, \alpha_{\mathrm{HbR}}$, and $\alpha_{0}$ are related to the concentration of oxygenated hemoglobin $C_{\mathrm{HbO}}$, that of deoxygenated hemoglobin $C_{\mathrm{HbR}}$, and the coefficient $a$, respectively. However, $\alpha_{\mathrm{HbO}}, \alpha_{\mathrm{HbR}}$, and $\alpha_{0}$ are not determined by a unique regression coefficient when using only MRA1. Thus, we used further multiple regression analysis to estimate the values of $C_{\mathrm{HbO}}, C_{\mathrm{HbR}}$, and $a$ on the basis of the combination of regression coefficients $\alpha_{\mathrm{HbO}}, \alpha_{\mathrm{HbR}}$, and $\alpha_{0}$ that were obtained from MRA1. In this analysis, $C_{\mathrm{HbO}}, C_{\mathrm{HbR}}$, and $a$ were regarded as response variables, and the three regression coefficients $\alpha_{\mathrm{HbO}}, \alpha_{\mathrm{HbR}}$, and $\alpha_{0}$ in Eq. (7) were regarded as predictor variables. Their relations are written as $C_{\mathrm{HbO}}=$ $\boldsymbol{\beta}_{\mathrm{HbO}} \cdot \boldsymbol{\alpha}, \quad C_{\mathrm{HbR}}=\boldsymbol{\beta}_{\mathrm{HbR}} \cdot \boldsymbol{\alpha}, \quad$ and $a=\boldsymbol{\beta}_{\mathbf{a}} \cdot \boldsymbol{\alpha}$, where $\boldsymbol{\alpha}=$ $\left[1, \alpha_{\mathrm{HbO}}, \alpha_{\mathrm{HbR}}, \alpha_{0}\right]^{\mathrm{T}}, \boldsymbol{\beta}_{\mathrm{HbO}}=\left[\beta_{\mathrm{HbO}, 0}, \beta_{\mathrm{HbO}, 1}, \beta_{\mathrm{HbO}, 2}, \beta_{\mathrm{HbO}, 3}\right], \boldsymbol{\beta}_{\mathrm{HbR}}=$ $\left[\beta_{\mathrm{HbR}, 0}, \beta_{\mathrm{HbR}, 1}, \beta_{\mathrm{HbR}, 2}, \beta_{\mathrm{HbR}, 3}\right]$, and $\boldsymbol{\beta}_{\mathbf{a}}=\left[\beta_{a, 0}, \beta_{a, 1}, \beta_{a, 2}, \beta_{a, 3}\right]$. The symbol []$^{\mathrm{T}}$ represents the transposition of a vector. The coefficients $\beta_{\mathrm{HbO}, i}, \beta_{\mathrm{HbR}, i}$, and $\beta_{a, i}(i=0,1,2,3)$ are unknown and must be determined before analysis. We adopted MCS as the foundation to establish reliable values of $\beta_{\mathrm{HbO}, i}, \beta_{\mathrm{HbR}, i}$, 
and $\beta_{a, i}$. We used the MCS source code developed by Wang et al., ${ }^{27}$ in which the Henyey-Greenstein phase function is applied to the sampling of the scattering angle of photons. The simulation model consisted of a single layer representing cortical tissue. In a single simulation of diffuse reflectance at each wavelength, 5,000,000 photons were randomly launched. The absorption coefficients of oxygenated hemoglobin $\mu_{a, \mathrm{HbO}}$ and deoxygenated hemoglobin $\mu_{a, \mathrm{HbR}}$ were obtained from the values of $\varepsilon_{\mathrm{HbO}}(\lambda)$ and $\varepsilon_{\mathrm{HbR}}(\lambda)$ in the literature, ${ }^{28}$ where the hemoglobin concentration of blood with a $44 \%$ hematocrit is $2326 \mu \mathrm{M}$ of hemoglobin. The absorption coefficient $\mu_{a}$ converted from the concentrations $C_{\mathrm{HbO}}$ and $C_{\mathrm{HbR}}$ and the reduced scattering coefficient $\mu_{\mathrm{s}}^{\prime}$ specified by the coefficient $a$ were provided as inputs to the simulation, while the diffuse reflectance was produced as output. The input concentrations and coefficient $a$ and the output reflectance are helpful as the dataset in specifying the values of $\beta_{\mathrm{HbO}, i}, \beta_{\mathrm{HbR}, i}$, and $\beta_{a, i}$ statistically for determining the absolute values of $C_{\mathrm{HbO}}, C_{\mathrm{HbR}}$, and $a$. The five different values of 40,172, 60,258, 80,344, 100,430, and 120,516 were calculated by multiplying the typical value $^{26}$ of $a$ by $0.5,0.75,1.0,1.25$, and 1.5 , respectively, and the reduced scattering coefficients $\mu_{\mathrm{s}}^{\prime}(\lambda)$ of the cortical tissue with the five different values were derived from the relation of Eq. (6). The sum of the absorption coefficients of $\mathrm{HbO}$ and $\mathrm{HbR}, \mu_{a, \mathrm{HbO}}+\mu_{a, \mathrm{HbR}}\left(\mu_{a, \mathrm{HbT}}\right)$, for $C_{\mathrm{HbT}}=4.65,23.3,116,233$, and $465 \mu \mathrm{M}$ was used as input to the cortical tissue in the simulation. Tissue oxygen saturation $\mathrm{StO}_{2}$ was determined by $\mu_{a, \mathrm{HbO}} / \mu_{a, \mathrm{HbT}}$ and values of $0,20,40,60,80$, and $100 \%$ were used for simulation. In total, 150 diffuse reflectance spectra at $\lambda=520,540,560,580$, and $600 \mathrm{~nm}$ were simulated under the various combinations of $C_{\mathrm{HbO}}, C_{\mathrm{HbR}}$, and $a$. MRA1 for each simulated spectrum based on Eq. (7) generated the 150 sets of vector $\alpha$ and $C_{\mathrm{HbO}}, C_{\mathrm{HbR}}$, and $a$. The coefficient vectors, also referred to as conversion vector, $\boldsymbol{\beta}_{\mathbf{H b O}}, \boldsymbol{\beta}_{\mathbf{H b R}}$, and $\boldsymbol{\beta}_{\mathbf{a}}$ were determined statistically by performing MRA2. Once $\boldsymbol{\beta}_{\mathrm{HbO}}, \boldsymbol{\beta}_{\mathrm{HbR}}$, and $\boldsymbol{\beta}_{\mathbf{a}}$ were obtained, $C_{\mathrm{HbO}}, C_{\mathrm{HbR}}$, and $a$ were calculated from $\alpha_{\mathrm{HbO}}, \alpha_{\mathrm{HbR}}$, and $\alpha_{0}$, which were derived from MRA1 for the measured reflectance spectrum, without the Monte Carlo simulation. Therefore, the spectrum of absorption coefficient $\mu_{a}(\lambda)$ and that of reduced scattering coefficient $\mu_{\mathrm{s}}^{\prime}(\lambda)$ was reconstructed by Eqs. (3) and (6), respectively, from the measured reflectance spectrum. The principle of the method was previously validated using tissue phantoms; ${ }^{21}$ the correlation between the given value of $\mu_{\mathrm{s}}^{\prime}$ and estimated value of $\mu_{\mathrm{s}}^{\prime}$ and that between the given value of $\mu_{a}$ and estimated value of $\mu_{a}$ were shown. We also compared the results of calculation of changes in $C_{\mathrm{HbO}}$ and $C_{\mathrm{HbR}}$ with those obtained by the conventional modified Lambert-Beer law analysis (see Sec. 5). As described above, since the light scattering signal can be used as an optical marker of CSD, we used maps of scattering amplitude a, which is proportional to $\mu_{\mathrm{s}}^{\prime}$, to visualize propagation of CSD in this study. To determine the propagation velocity of $\mathrm{CSD}$, reflectance images at $800 \mathrm{~nm}$ were used since they are also sensitive to light scattering changes due to $\mathrm{CSD}^{5}$

\subsection{Evaluation of Cortical Vessel Diameters}

To assess changes in diameters of cortical arterioles and venules, we used reflectance images at $520 \mathrm{~nm}$, which is an isosbestic point of $\mathrm{HbO}$ and $\mathrm{HbR}$. For the cortical image, we placed a linear line that was perpendicularly across the centerline of the vessel of interest on LabVIEW software (see white and red lines on the top image in Fig. 5), creating an image intensity profile of the vessel. Vessel diameter was defined as the FWHM value of the profile. ${ }^{29,30,31}$ Arterioles and venules were distinguished on the basis of their diameters, positions, orientations, and values of $\mathrm{StO}_{2}$ before LISW application. In addition, we carefully distinguished cortical surface arterioles from the vessels in the dura matter on the basis of their diameters; the diameter of cortical surface arterioles is about two to three times larger than that of dural vessels $(\sim 25 \mu \mathrm{m})$ in their proximal portion in rats. ${ }^{23}$

\subsection{Statistical Analysis}

Statistical methods for data obtained in this study were selected on the basis of analysis of data normality and uniformity of variance using the Ekuseru-Toukei 2012 statistical software package (Social Survey Research Information Co., Ltd., Tokyo, Japan). With regard to changes in diameters of pial arterioles and venules, results were compared using the nonparametric Dunn's multiple comparisons test. Changes in $\mathrm{rC}_{\mathrm{Hb}}$ and $\mathrm{StO}_{2}$ were tested by the parametric Dunnett's multiple comparisons test or the nonparametric Dunn's multiple comparisons test.

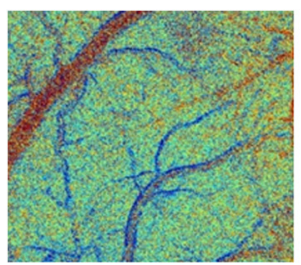

$1 \min 21 \mathrm{~s}$

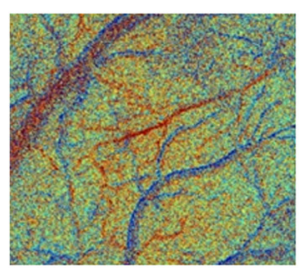

$2 \min 9 s$

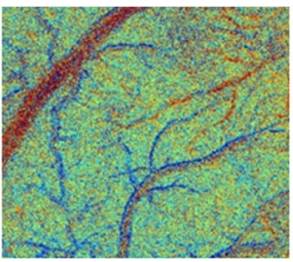

$1 \min 31 \mathrm{~s}$

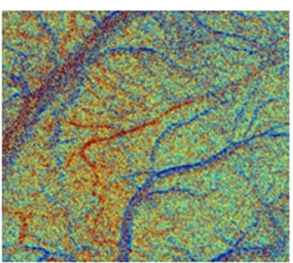

$2 \min 19 s$

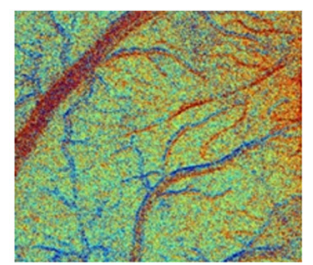

$1 \min 41 \mathrm{~s}$

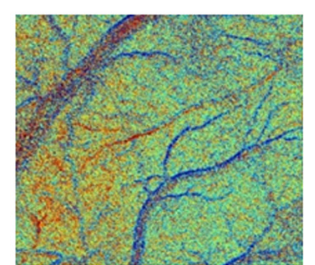

$2 \min 29 s$

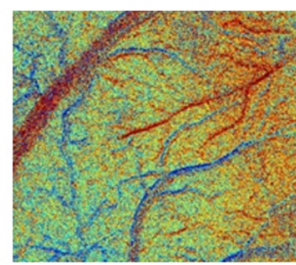

$1 \min 50 s$

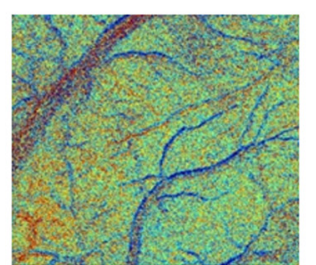

$2 \min 39 s$

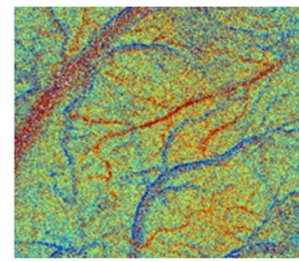

$2 \min$

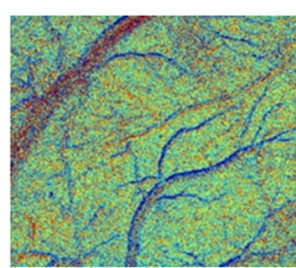

$2 \min 48 s$

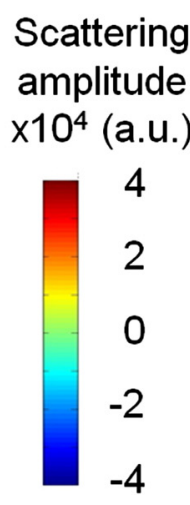

Fig. 3 Difference images of scattering amplitude during CSD propagation for rat no. 3. Pixel sizes in the images are $455 \times 418$; the imaging field of view corresponds to $\sim 2.6 \times 2.4 \mathrm{~mm}$. Each time indicates the time after LISW application. 
Changes in OEF were tested by the parametric Tukey's multiple comparisons test. The multiple comparison tests were performed using GraphPad Prism software (Prism 6 for Windows, GraphPad software, Inc., La Jolla, California); a difference was considered statistically significant when $p<0.05$. Data are presented as means \pm standard deviation (SD) when the parametric method was used, and data are presented as medians with ranges (in box plots) when the nonparametric method was selected.

\section{Results}

\subsection{Spatiotemporal Changes in Scattering Amplitude Associated with Cortical Spreading Depolarization}

In our previous studies, we showed that light scattering signals can be used as an optical marker of CSD. ${ }^{5}$ Figure 3 shows

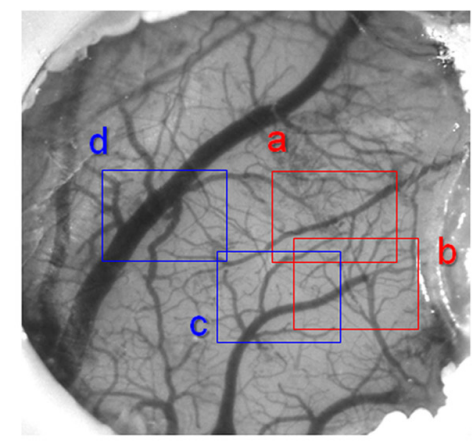

\section{Before LISW application}

(a)

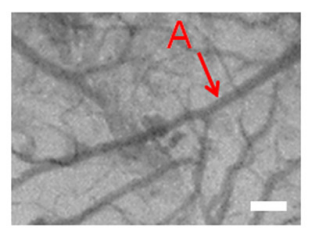

(b)

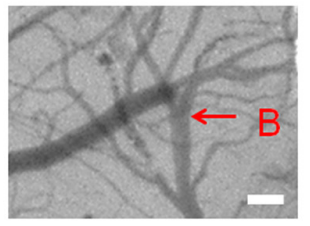

\section{Before LISW application}

(c)

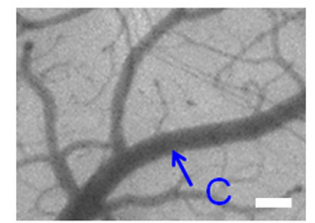

(d)

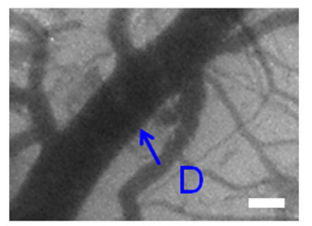

Immediately after LISW application
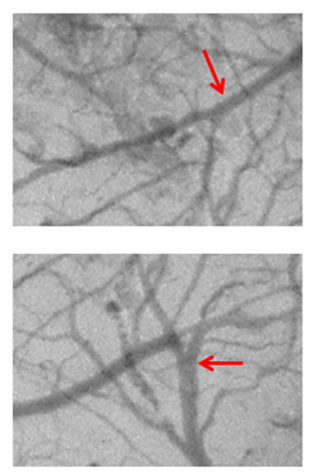

Immediately after LISW application
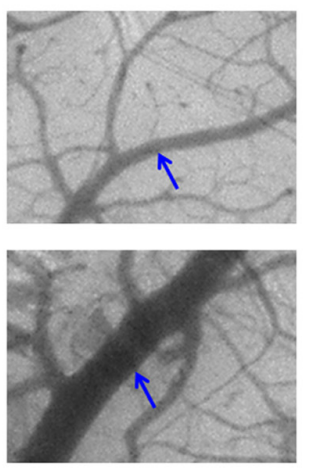

During CSD propagation
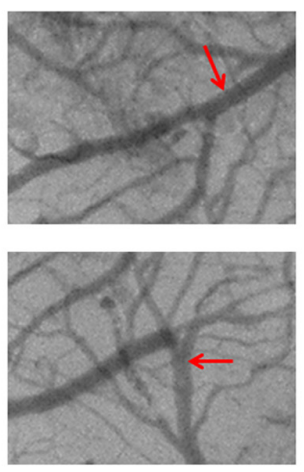

During CSD propagation
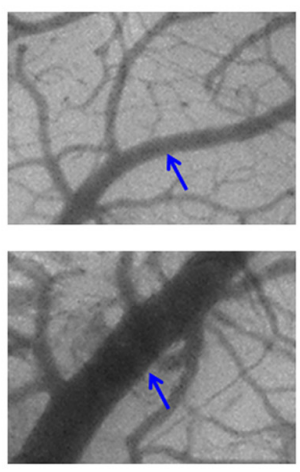

\section{Direction of CSD propagation}
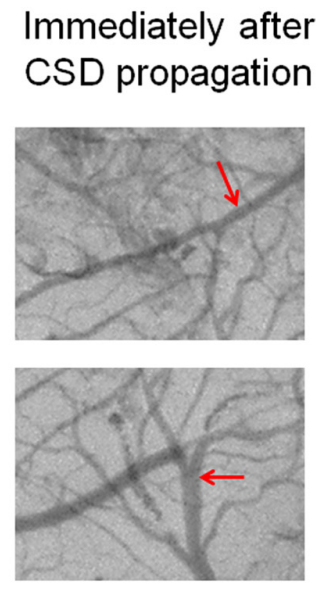

Immediately after CSD propagation
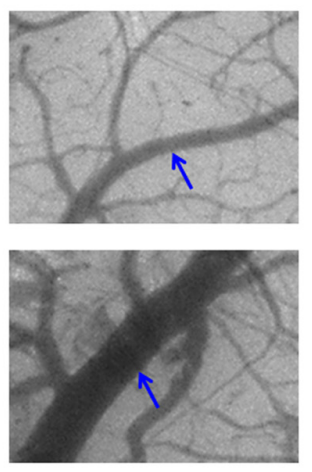

Fig. 4 Representative reflectance images at $520 \mathrm{~nm}$ of four different regions before and after LISW application in rat no. 3. Region (a) shows a pial arteriole (A), which is anterograde to the direction of CSD propagation, with red arrows. Region (b) shows another pial arteriole (B), which is perpendicular to the direction of CSD propagation, with red arrows. Region (c) and region (d) show pial venules (C) and (D), respectively, with blue arrows; region (c) shows a relatively small venule and region (d) shows a large venule. Pixel sizes in the images $(\mathrm{a}-\mathrm{d})$ are $165 \times 121$. Each bar in the image before LSIW application represents $100 \mu \mathrm{m}$. Each position of (a) to (d) and direction of CSD propagation are shown at the top. 
difference images of scattering amplitude in the rat cortex after exposure to an LISW, where the image before LISW application is subtracted from the image at each timepoint (rat no. 3). After LISW application, a large venule showed an increase in scattering amplitude, and the region with increased scattering amplitude appeared in the parenchyma and in the pial arterioles in the right edge of the region of interest (RoI) (anterior side of the cortex) at $1 \mathrm{~min} 21 \mathrm{~s}$ after LISW application. The region with increased scattering amplitude in the parenchyma and arterioles was propagating like a wave to the left (posterior side), indicating a propagation of CSD. Such CSD-related scattering change was observed in all four rats examined, and only in one (a)

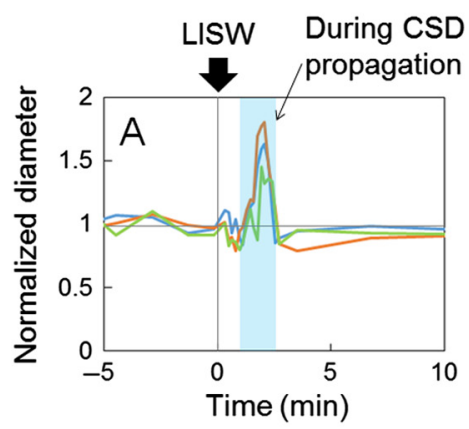

(b)

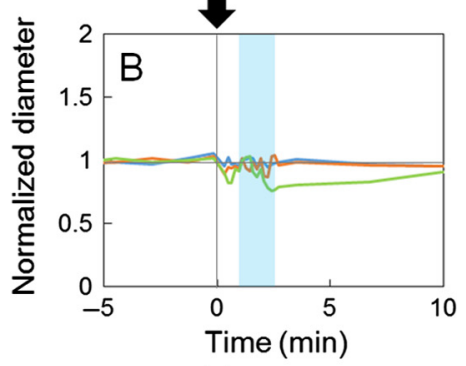

(c)

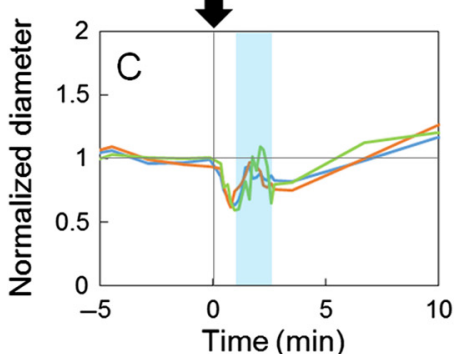

(d)

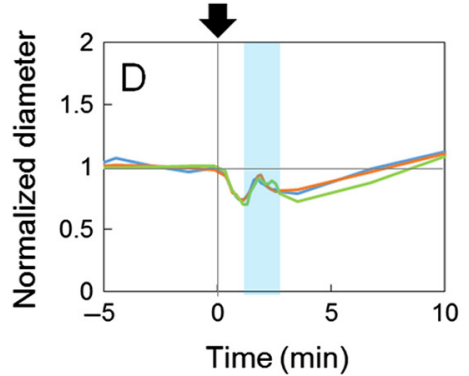

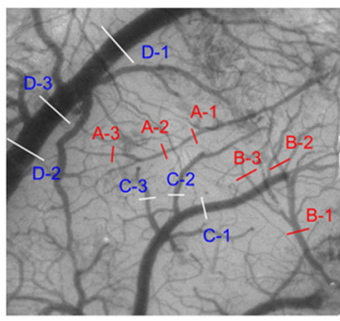

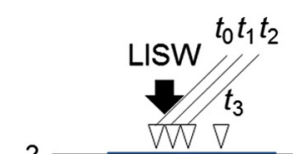

$t_{4}$

$t_{5}$
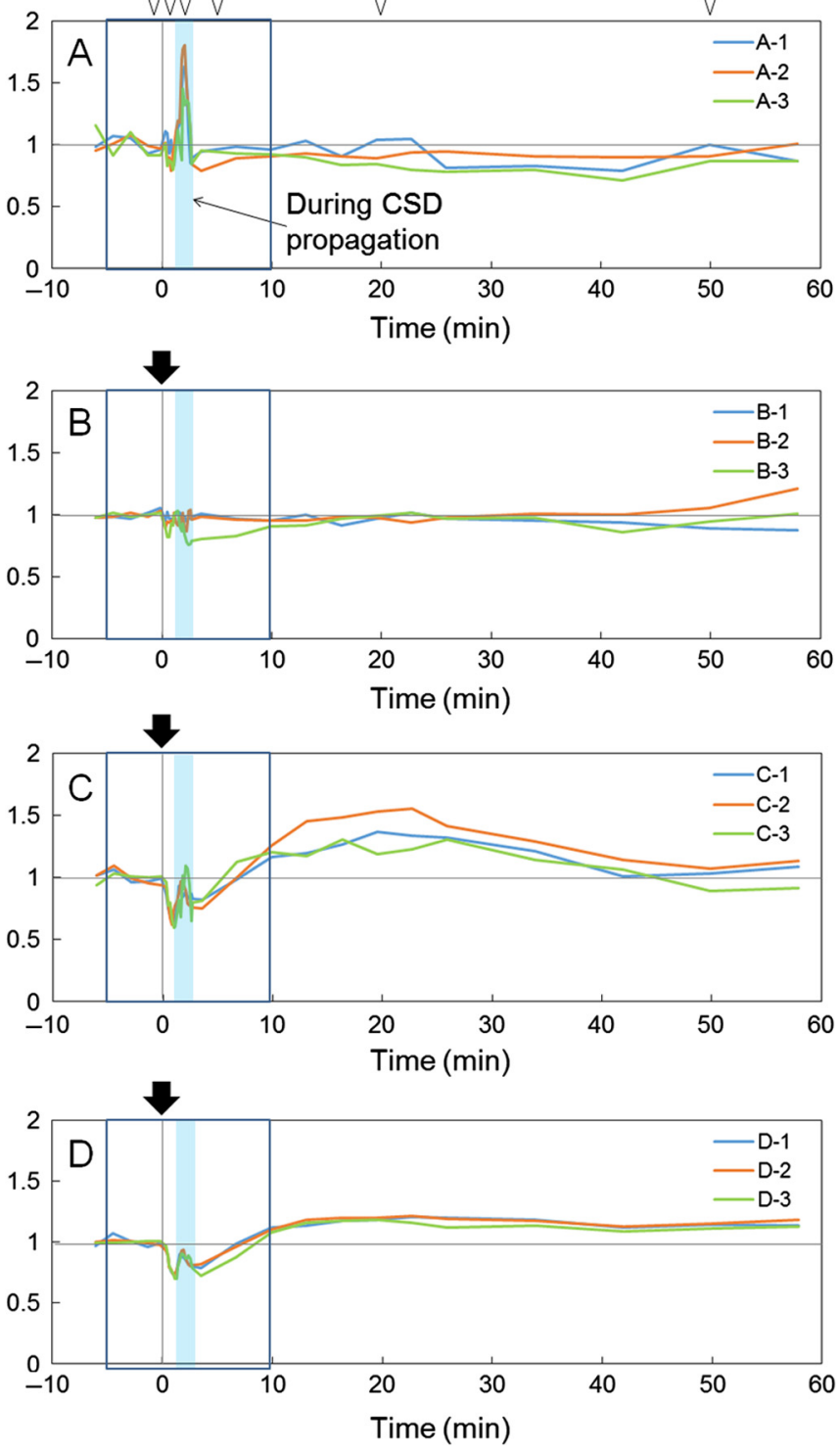

Fig. 5 Time courses of changes in diameters of pial arterioles and venules after LISW application for rat no. 3; diameters were normalized by average diameters before LISW application. (a) Arteriole A anterograde to the direction of CSD propagation (A-1 to 3). (b) Arteriole B perpendicular to the direction of CSD propagation (B-1 to 3). (c) Venule $C$ with a small diameter (C-1 to 3). (d) Venule D with a large diameter (D-1 to 3). Each position to measure the diameter is shown in the top image. Each graph on the left side is a magnified view of the bold-lined square of the graph on the right side. Arrowheads from $t_{1}$ to $t_{5}$ show timepoints for analysis in Figs. 6, 9, and 10. 
rat (rat no. 4), the second consecutive wave of CSD was seen at $5 \mathrm{~min} 45 \mathrm{~s}$ after the start of the first wave. The propagation velocity of the wavefront of the first CSD wave in the parenchyma was $2.96 \pm 0.55 \mathrm{~mm} / \min ($ mean $\pm \mathrm{SD})(n=4)$, being consistent with the results of our previous study ${ }^{5}$ and other studies using $\mathrm{KCl}$ injection or pinprick to induce CSD. ${ }^{15,16,32}$

\subsection{Vasculature Morphological Changes}

Figure 4 shows images at $520 \mathrm{~nm}$, an isosbestic wavelength of $\mathrm{HbO}$ and $\mathrm{HbR}$, of pial arterioles and venules before and after exposure to an LISW in the same rat, as that shown in Fig. 3 (rat no. 3). Vessel type-dependent morphological changes were seen. A pial arteriole marked "A" that is running in the anterograde direction to the CSD propagation direction showed almost no change in diameter just after LISW application but showed distinct vasodilatation during the CSD propagation and then recovered soon after the CSD propagation [Fig. 4(a)]. Such vasodilatation during CSD was not observed in the pial arteriole marked " $\mathrm{B}$ " that is running perpendicular to the CSD propagation direction [Fig. 4(b)]. Pial venules observed through the cranial window were all anatomically perpendicular to or retrograde to the CSD propagation direction, while their initial diameters were greatly different. Thus, we divided them into two groups: smaller-diameter (less than $80 \mu \mathrm{m}$ ) pial venules such as that marked "C" and larger-diameter $(80 \mu \mathrm{m}$ or more $)$ pial venules (a)

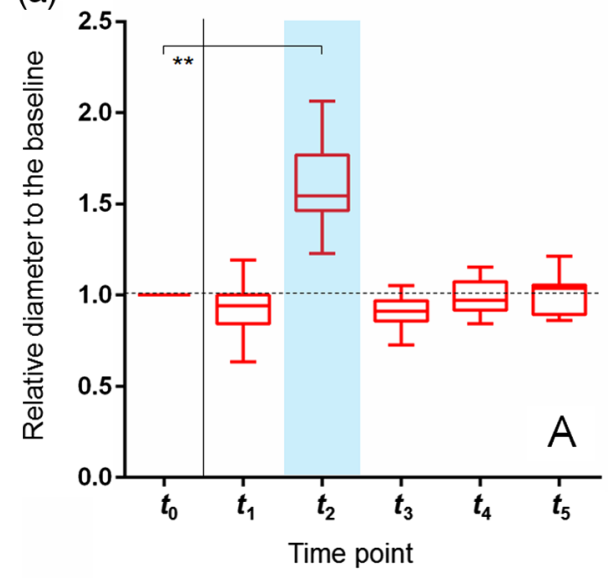

(c)

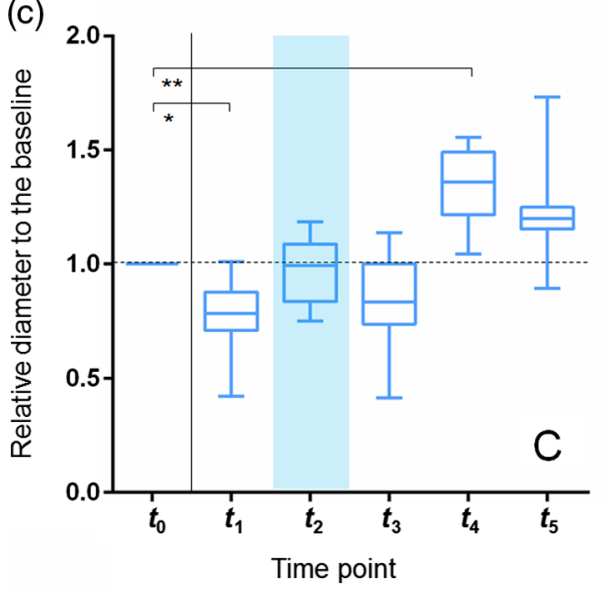

(b)

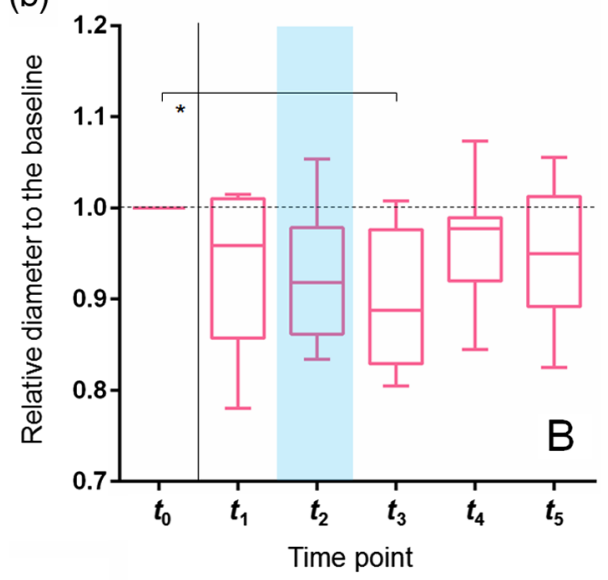

(d)

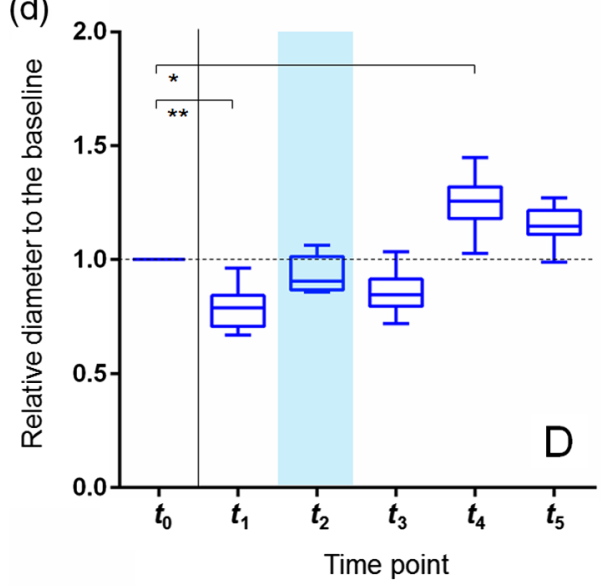

\begin{tabular}{|c|c|c|c|c|c|}
\hline$t_{0}$ & $t_{1}$ & $t_{2}$ & $t_{3}$ & $t_{4}$ & $t_{5}$ \\
\hline $\begin{array}{l}\text { Before LISW } \\
\text { application }\end{array}$ & $\begin{array}{l}\text { Immediately } \\
\text { after LISW } \\
\text { application }{ }^{1}\end{array}$ & $\begin{array}{l}\text { During CSD } \\
\text { propagation }^{2}\end{array}$ & $\begin{array}{l}\text { Immediately } \\
\text { after CSD } \\
\text { propagation }\end{array}$ & $\begin{array}{c}\sim 20 \text { min post- } \\
\text { CSD }\end{array}$ & $\begin{array}{c}\sim 50 \text { min post- } \\
\text { CSD }\end{array}$ \\
\hline
\end{tabular}

1 time point just before CSD propagation

2 time point when the arteriole reaches maximum diameter

Fig. 6 Relative changes in diameters of pial arterioles and venules at five time points after LISW application from the baseline for four rats examined; description for each time point is shown at the bottom of the graphs. (a) Arteriole A anterograde to the direction of CSD propagation. (b) Arteriole B perpendicular to the direction of CSD propagation. (c) Venule C with a diameter less than $80 \mu \mathrm{m}$. (d) Venule D with a diameter of $80 \mu \mathrm{m}$ or more. The horizontal dashed line in each graph shows the baseline before LISW application. Numbers of positions for vessel diameter measurements in rat no. 1, no. 2, no. 3, and no. 4 are as follows: (a) arteriole A, 3, 6, 3, and 2; (b) arteriole B, 2, 0, 3, and 3; (c) venules C, 5, 4, 4, and 4; (d) venule $D, 4,2,4$, and 2 , respectively. Data are presented as medians with ranges. Asterisks $(* p<0.05, * * p<0.01)$ indicate a statistically significant difference (Dunn's multiple comparisons test). 
such as that marked "D." Both types of venules showed distinct constriction immediately after LISW application regardless of their orientations and distances from the site of LISW application [Figs. 4(c) and 4(d)]; smaller-diameter venule C appeared to be more prominently constricted. The constrictions in both types of venules tended to recover during CSD propagation, but both types of venules reconstricted after the CSD propagation.

Figure 5 shows time courses of changes in diameters of each type of arteriole and venule for $\sim 60 \mathrm{~min}$ after LISW application (rat no. 3), for which we randomly selected three positions on each arteriole/venule shown in Fig. 4. The diameter of arteriole A slightly increased and then decreased by $10 \%$ to $15 \%$ over a period of $1 \mathrm{~min}$ after LISW application and then suddenly increased by a maximum of $\sim 80 \%$ concomitantly with the propagation of CSD. Soon after CSD propagation, the diameter recovered and thereafter it remained at the baseline level or decreased by $5 \%$ to $30 \%$ until the end of the measurement. In arteriole B, the diameter was limitedly changed at two (a)

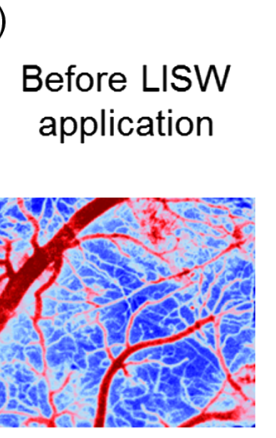

Total $\mathrm{Hb}$

concentration $(\mu \mathrm{M})$
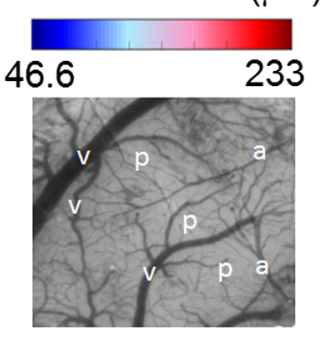

(b)

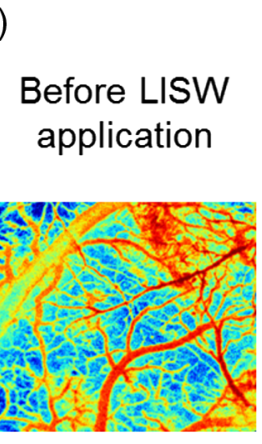

Tissue oxygen saturation $(\%)$
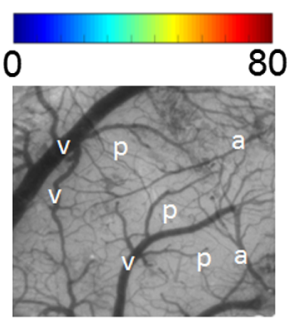

Immediately after LISW

application

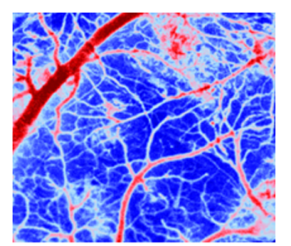

$1 \min 11 \mathrm{~s}$

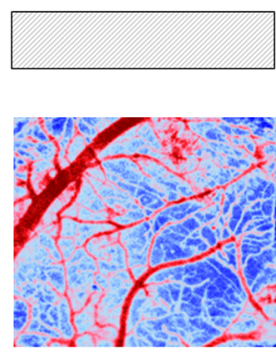

$2 \min 29 \mathrm{~s}$

Immediately

after LISW

application

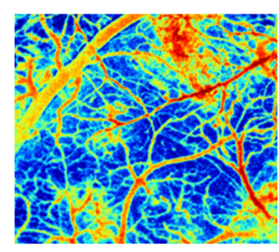

$1 \min 11 \mathrm{~s}$
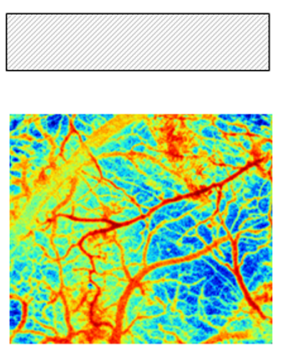

$2 \min 29 \mathrm{~s}$

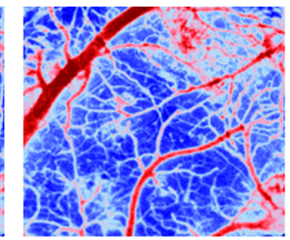

$1 \min 21 \mathrm{~s}$

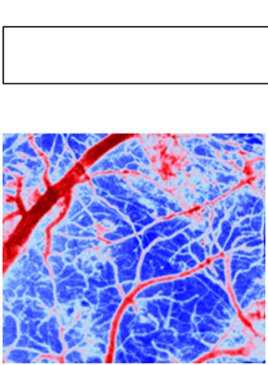

$3 \mathrm{~min} 26 \mathrm{~s}$

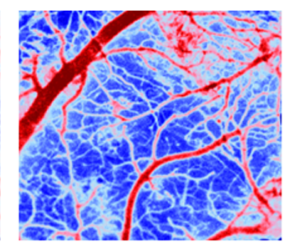

$1 \mathrm{~min} 31 \mathrm{~s}$

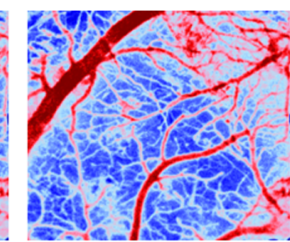

$1 \min 50 \mathrm{~s}$

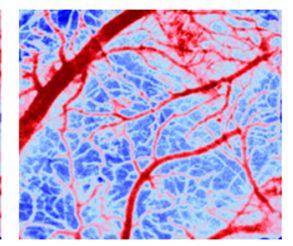

$2 \min 9 \mathrm{~s}$

After CSD propagation

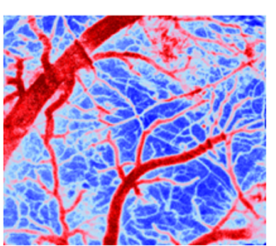

$17 \min 50 \mathrm{~s}$

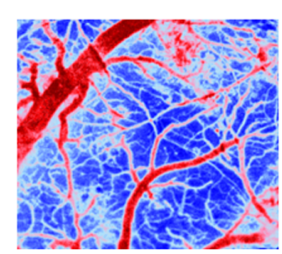

$41 \min 49 \mathrm{~s}$

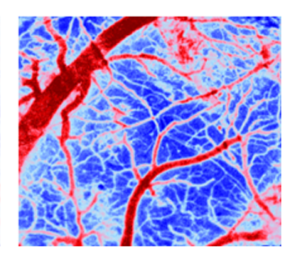

$66 \min 37 \mathrm{~s}$

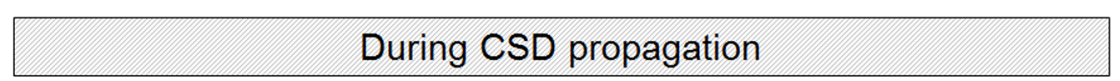

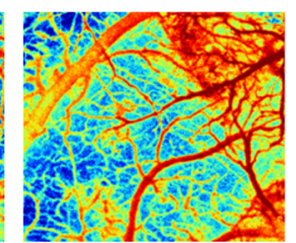

$1 \mathrm{~min} 21 \mathrm{~s}$

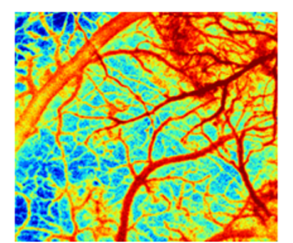

$1 \mathrm{~min} 31 \mathrm{~s}$

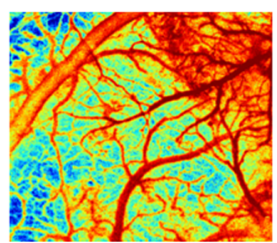

$1 \mathrm{~min} 50 \mathrm{~s}$

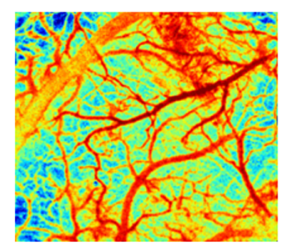

$2 \min 9 \mathrm{~s}$

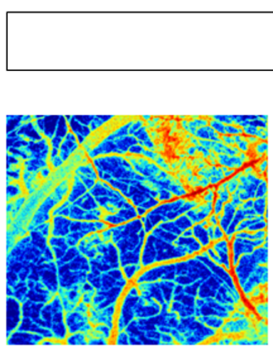

$3 \min 26 s$

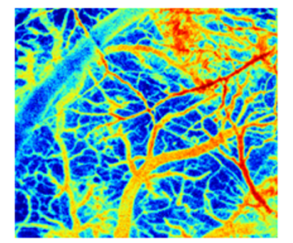

$17 \min 50 \mathrm{~s}$

After CSD propagation

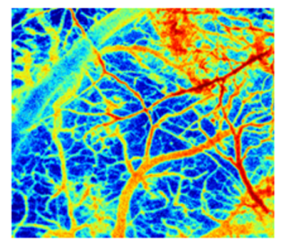

$41 \min 49 \mathrm{~s}$

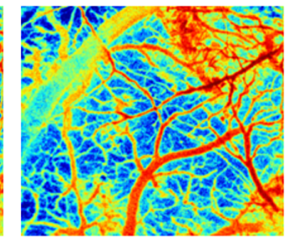

$66 \min 37 \mathrm{~s}$

Fig. 7 Maps of (a) regional hemoglobin concentration $\left(\mathrm{rC}_{\mathrm{Hb}}\right)$ and (b) tissue oxygen saturation $\left(\mathrm{StO}_{2}\right)$ before and after LISW application for rat no. 3. The bottom left images in (a) and (b) are corresponding reflectance images at $520 \mathrm{~nm}$ before LISW application, showing identification of arterioles, venules, and parenchyma as "a," "v," and "p," respectively. Pixel sizes in the images are $455 \times 418$. 
positions (B-1 and B-2) over a period of $\sim 50$ min after LISW application [Fig. 5(b)]. At the other position (B-3), however, the diameter decreased by $\sim 20 \%$ immediately after LISW application but transiently recovered. During CSD propagation, the diameter decreased again by $\sim 30 \%$, after which the diameter gradually recovered to the baseline. In pial venules $\mathrm{C}$ and $\mathrm{D}$, on the other hand, the diameters decreased by $\sim 45 \%$ and $\sim 25 \%$, respectively, over a period of $\sim 1 \mathrm{~min}$ soon after LISW application and then both increased almost concomitantly with the propagation of CSD over a period of $\sim 1$ min. Immediately after the CSD propagation, they decreased again by $20 \%$ to $30 \%$ from the baseline over a period of $\sim 1 \mathrm{~min}$ and then started to recover [Figs. 5(c) and 5)d)]. Interestingly, the diameters started to increase from the baseline at $\sim 7 \mathrm{~min}$ after LISW application and reached $120 \%$ to $155 \%$ at $\sim 20 \mathrm{~min}$; the smaller venules showed larger variations in their diameters. Thereafter, the diameters gradually decreased in smaller venule $\mathrm{C}$ but showed little changes in larger venule D.

On the basis of the time courses of vessel diameters shown in Fig. 5, six characteristic time points were determined: $t_{0}$, before LISW application; $t_{1}$, immediately after LISW application; $t_{2}$, during CSD propagation; $t_{3}$, immediately after CSD propagation; $t_{4}, \sim 20 \mathrm{~min}$ post-CSD; and $t_{5}, \sim 50 \mathrm{~min}$ post-CSD [see arrowheads at the top of Fig. 5(a)]. Figure 6 shows changes in diameters of pial arterioles and venules relative to the baseline diameters (values before LISW application, $t_{0}$ ) at these time points for all four rats examined. For this analysis, we randomly selected a total of 14 positions from 5 arterioles for type A (running anterograde to the CSD propagation direction), 8 positions from 3 arterioles for type B (running perpendicular to or retrograde to the CSD propagation direction), 17 positions from 8 venules for type $\mathrm{C}$ (with a diameter less than $80 \mu \mathrm{m}$ ), and 10 positions from 7 venules for type $\mathrm{D}$ (with a diameter of $80 \mu \mathrm{m}$ or more); all of the observable arterioles and venules were evaluated. The mean diameters before LISW application were $48 \pm 4 \mu \mathrm{m} \quad(n=14, \quad$ mean $\pm \mathrm{SEM})$ and $44 \pm 5 \mu \mathrm{m}$ $(n=8)$ for type $\mathrm{A}$ and type $\mathrm{B}$ arterioles and $53 \pm 4 \mu \mathrm{m}$ $(n=17)$ and $150 \pm 13 \mu \mathrm{m}(n=12)$ for type $\mathrm{C}$ and type $\mathrm{D}$ venules, respectively. Unique responses depending on the vascular type were seen in all rats examined. The diameter of type A arterioles showed a significant increase at $t_{2}$ and the percent increase was $59 \pm 9 \%$ (mean \pm SEM). For type B arterioles, however, the diameter did not show a significant change at $t_{2}$ but was significantly decreased at $t_{3}(-10 \pm 3 \%)$. For both C and D types of venules, the diameters were significantly decreased at $t_{1}(-22 \pm 4 \%$ and $-20 \pm 2 \%$, respectively). After the propagation of CSD, both $\mathrm{C}$ and $\mathrm{D}$ types of venules showed significant increases at $t_{4}(34 \pm 4 \%$ and $25 \pm 3 \%$, respectively). Vascular responses to the second consecutive $\mathrm{CSD}$, which were observed only for rat no. 4 , were excluded from analysis in this study.

\subsection{Regional Hemoglobin Concentration and Tissue Oxygen Saturation}

Figure 7 shows false-color maps of the distributions of $\mathrm{rC}_{\mathrm{Hb}}$ and $\mathrm{StO}_{2}$ before and after LISW application (rat no. 3; see also Fig. 8 for $\mathrm{StO}_{2}$ ). The maps clearly show site-dependent variations in $\mathrm{rC}_{\mathrm{Hb}}$ and $\mathrm{StO}_{2}$ among the arterioles, venules, and parenchyma. Immediately after LISW application $(t=1 \min 11 \mathrm{~s})$, both $\mathrm{rC}_{\mathrm{Hb}}$ and $\mathrm{StO}_{2}$ decreased in almost all regions; their decreases in the parenchyma were remarkable and pial venules showed distinct constriction. Thereafter, $\mathrm{rC}_{\mathrm{Hb}}$ and $\mathrm{StO}_{2}$ started to increase in the right side region ( $t=1 \mathrm{~min} 21 \mathrm{~s})$, and the regions with increased
$\mathrm{rC}_{\mathrm{Hb}}$ and $\mathrm{StO}_{2}$ were moving to the left side, corresponding to the propagation of CSD (until $t=2 \min 29 \mathrm{~s}$ ), indicating hyperemic responses to CSD (see Fig. 3). After the CSD propagation, $\mathrm{rC}_{\mathrm{Hb}}$ and $\mathrm{StO}_{2}$ started to drastically decrease ( $t=3$ min $26 \mathrm{~s}$ ). Thereafter, $\mathrm{rC}_{\mathrm{Hb}}$ tended to gradually recover but still continued to be lower than the values before LISW application in the parenchymal region $(t=66 \min 37 \mathrm{~s})$. On the other hand, $\mathrm{StO}_{2}$ remained very low in all regions; the values in the parenchyma and venules were especially low until $\sim 40$ min postCSD and those in the parenchyma at $\sim 1 \mathrm{~h}$ post-CSD were still lower than the values before LISW application.

Figure 9 shows changes in $\mathrm{rC}_{\mathrm{Hb}}$ and $\mathrm{StO}_{2}$ in the parenchyma, arterioles, and venules at the six characteristic time points shown in Figs. 5 and 6 for all four rats examined, for which a total of 68 RoIs, including 24 RoIs in the parenchyma, 20 RoIs in arterioles running anterograde to the CSD propagation direction, and 24 RoIs in venules, were sampled. Immediately after LISW application (at $t_{1}$ ), $\mathrm{rC}_{\mathrm{Hb}}$ was significantly decreased in all of the regions, by $\sim 8 \%$ in the parenchyma, by $\sim 6 \%$ in arterioles, and by $\sim 8 \%$ in venules from the baseline levels. During CSD propagation (at $t_{2}$, light blue shadow), $\mathrm{rC}_{\mathrm{Hb}}$ was significantly increased in the parenchyma by $\sim 21 \%$ and in arterioles by $\sim 22 \%$, and then immediately after CSD propagation (at $t_{3}$ ), $\mathrm{rC}_{\mathrm{Hb}}$ was significantly decreased in the parenchyma, arterioles, and venules by $\sim 6 \%$, by $\sim 4 \%$, and by $\sim 8 \%$, respectively. At $t_{4}$ and $t_{5}$ (more than $\sim 20$ min post-CSD), while $\mathrm{rC}_{\mathrm{Hb}}$ in the arterioles at $t_{5}$ was significantly decreased, $\mathrm{rC}_{\mathrm{Hb}}$ had recovered to the baseline levels in the parenchyma and venules and did not change significantly. Corresponding to these $\mathrm{rC}_{\mathrm{Hb}}$ changes, $\mathrm{StO}_{2}$ also changed, but its behavior was more complex. At $t_{1}, \mathrm{StO}_{2}$ was significantly decreased in all of the regions by $\sim 29 \%$ in the parenchyma, by $\sim 4 \%$ in arterioles, and by $\sim 14 \%$ in venules from the baseline levels, but at $t_{2}$, it was significantly increased in these regions by $\sim 64 \%, \sim 14 \%$, and $\sim 19 \%$ from the baseline levels, respectively. At $t_{3}, \mathrm{StO}_{2}$ was significantly decreased by $\sim 46 \%$ in the parenchyma, by $\sim 10 \%$ in arterioles, and by $\sim 16 \%$ in venules from the baseline levels. After the CSD propagation (at $t_{4}$ and $t_{5}$ ), $\mathrm{rC}_{\mathrm{Hb}}$ recovered

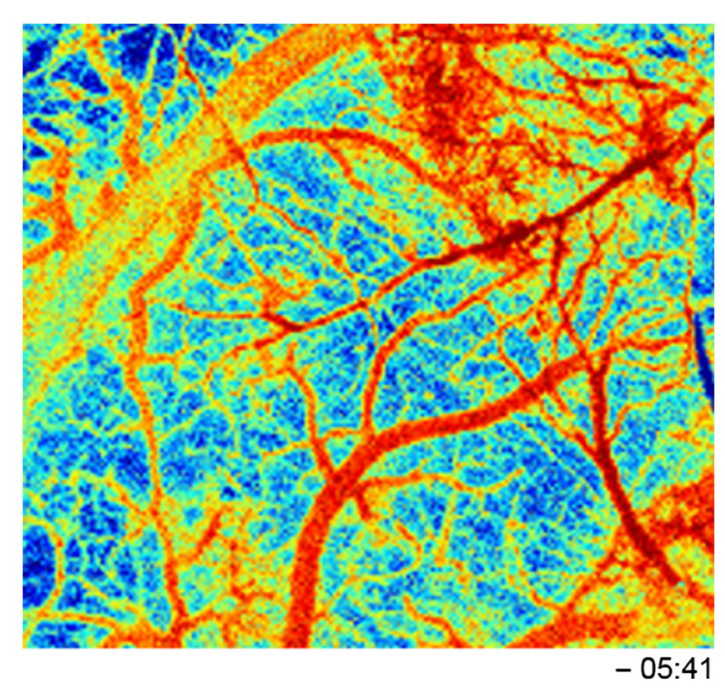

Fig. 8 Tissue oxygen saturation $\left(\mathrm{StO}_{2}\right)$ map before and after LISW application for rat no. 3 corresponding to Fig. 7 . Time (mm:ss) in the bottom right indicates the time after LISW application; minus means before LISW application [MPEG, 6.0 MB (URL: https://doi .org/10.1117/1.JBO.24.3.035005.1)]. 

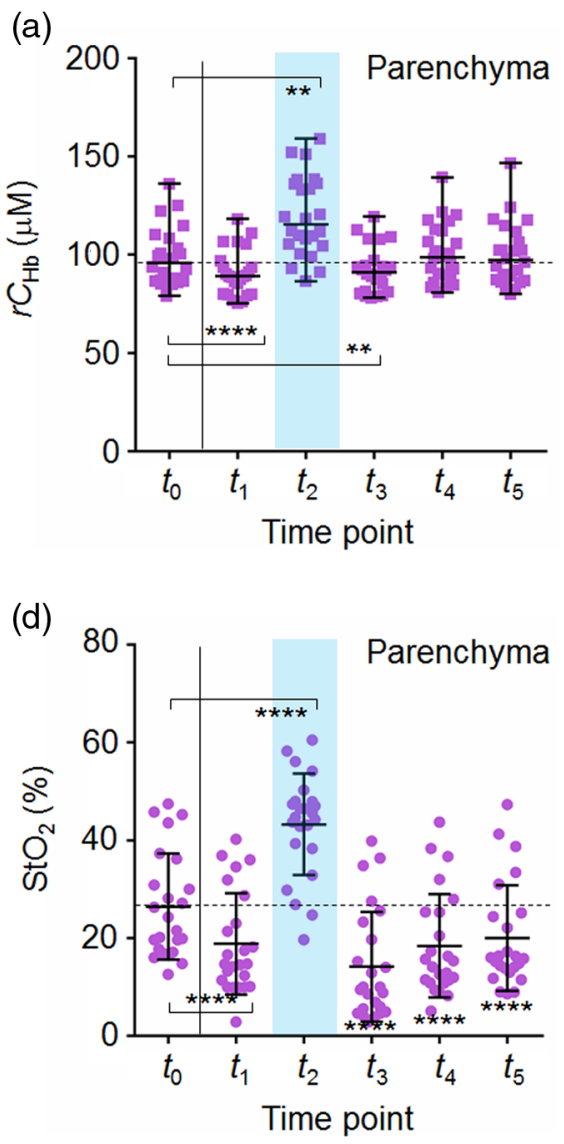
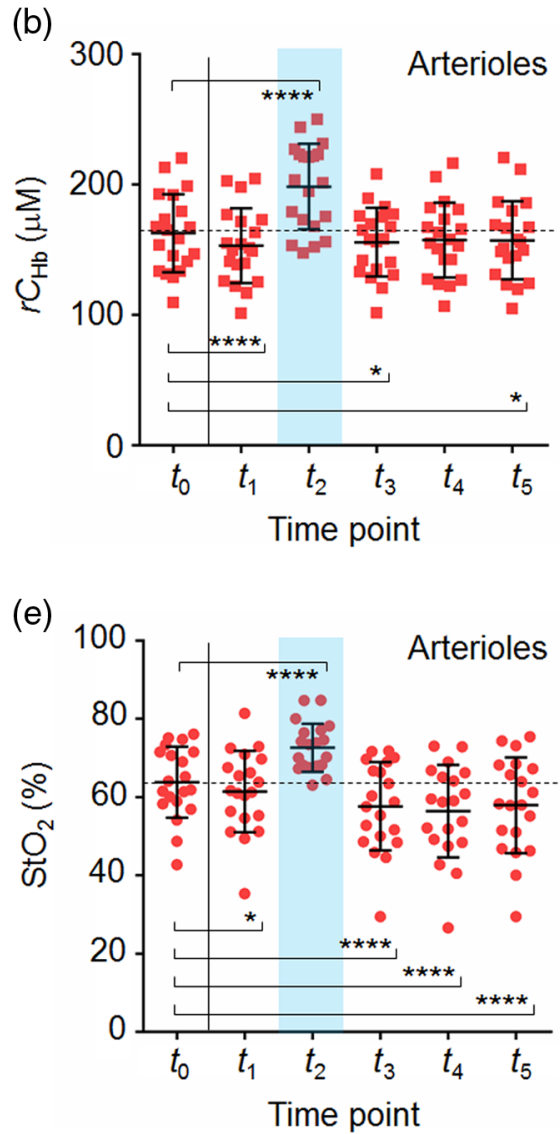
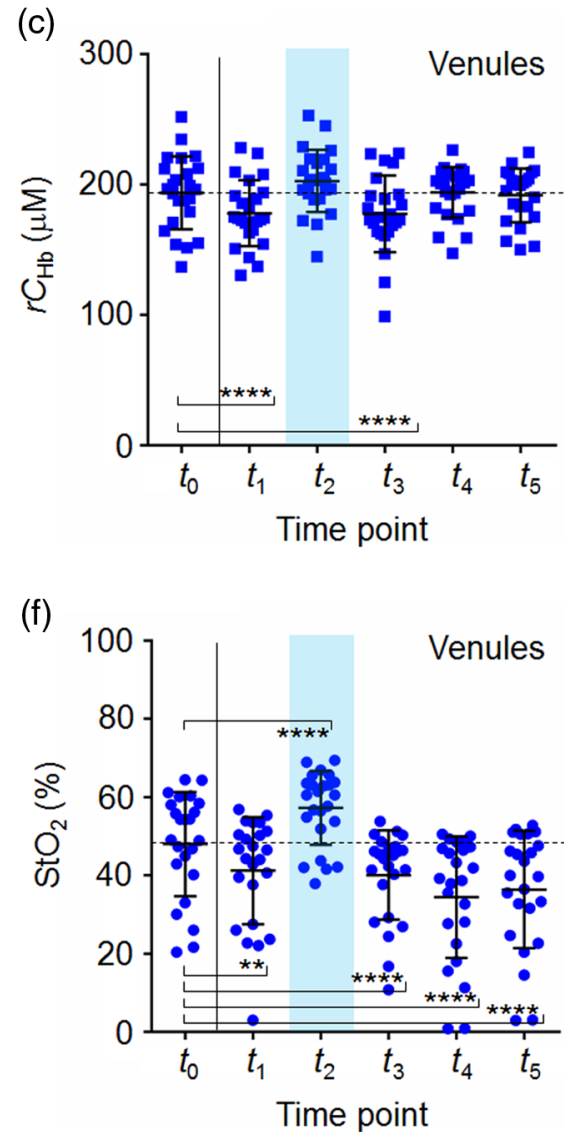

(g)

\begin{tabular}{|c|c|c|c|c|c|c|c|}
\hline & $t_{0}$ & $t_{1}$ & & & $t_{3}$ & $t_{4}$ & $t_{5}$ \\
\hline \multirow[t]{2}{*}{$\mathrm{SpO}_{2}(\%)$} & \multirow[t]{2}{*}{$90.5 \pm 0.3$} & $91.8 \pm 0.6$ & \multicolumn{2}{|c|}{$90.0 \pm 0.7$} & \multirow[t]{2}{*}{$87.0 \pm 3.4$} & $92.3 \pm 0.3$ & $91.3 \pm 0.9$ \\
\hline & & & & & & \multicolumn{2}{|c|}{$($ Mean \pm SEM) } \\
\hline $\mathrm{t}_{0}$ & $t_{1}$ & & & & $t_{3}$ & $t_{4}$ & $t_{5}$ \\
\hline $\begin{array}{l}\text { Before LISW } \\
\text { application }\end{array}$ & $\begin{array}{l}\text { Immediately } \\
\text { after LISW } \\
\text { application }\end{array}$ & $\begin{array}{l}\text { Durin } \\
\text { propa }\end{array}$ & $\begin{array}{l}\mathrm{CSD} \\
\text { ation }^{2}\end{array}$ & $\begin{array}{r}\text { Imm } \\
\text { aft } \\
\text { prop }\end{array}$ & $\begin{array}{l}\text { ediately } \\
\text { er CSD } \\
\text { agation }\end{array}$ & $c$ & $\begin{array}{l}\sim 50 \text { min post- } \\
\text { CSD }\end{array}$ \\
\hline
\end{tabular}

1 time point just before CSD propagation

2 time point when the arteriole reaches maximum diameter

Fig. 9 Regional hemoglobin concentration $\left(\mathrm{rC}_{\mathrm{Hb}}\right)$, tissue oxygen saturation $\left(\mathrm{StO}_{2}\right)$, and arterial oxygen saturation measured at the hindlimb before and after LISW application for four rats examined; description for each time point is shown at the bottom of the graphs. (a-c) $\mathrm{rC}_{\mathrm{Hb}}$ in the parenchyma (a), pial arterioles (b), and pial venules (c). (d-f) Corresponding $\mathrm{StO}_{2}$ in the parenchyma (d), pial arterioles (e), and pial venules $(\mathrm{f})$. $(\mathrm{g})$ Arterial oxygen saturation $\left(\mathrm{SpO}_{2}\right)$ simultaneously measured at the hindlimb. The horizontal dashed line in each graph shows the baseline before LISW application. Numbers of Rols used for analysis in rat no. 1 , no. 2, no. 3, and no. 4 are as follows: $6,6,6$, and 6 for parenchyma; $4,6,4$, and 6 for arterioles; $6,6,6$, and 6 for venules, respectively. $\mathrm{rC}_{\mathrm{Hb}}$ levels in the parenchyma (a) are presented as medians with ranges; Dunn's multiple comparisons test was performed. Other data are presented as means $\pm \mathrm{SD}$; Dunnett's multiple comparisons test was performed. Asterisks $(* p<0.05, * * p<0.01$, $* * * * p<0.0001)$ indicate a statistically significant difference. 


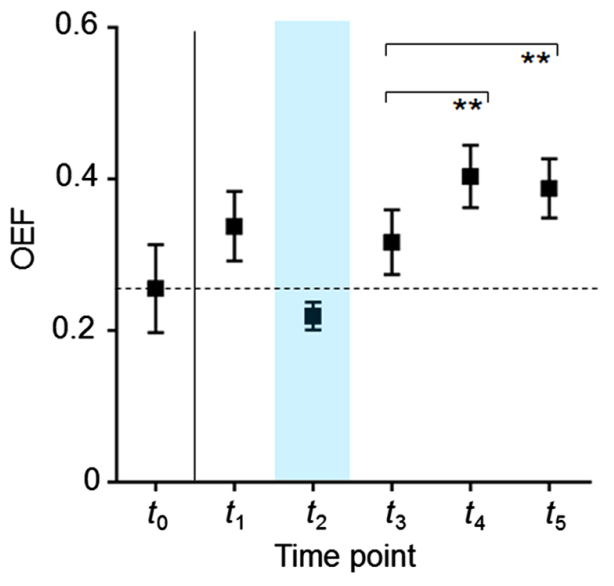

Fig. 10 OEF at the same time points as in Figs. 6 and 9 after LISW application for four rats examined: $t_{0}$, before LISW application; $t_{1}$, immediately after LISW application; $t_{2}$, during CSD propagation (with blue shadow); $t_{3}$, immediately after CSD propagation; $t_{4}$, $\sim 20 \mathrm{~min}$ post-CSD; $t_{5}, \sim 50 \mathrm{~min}$ post-CSD. The horizontal dashed line shows the baseline before LISW application. Data are presented as means $\pm \operatorname{SD}(n=4)$; Tukey's multiple comparisons test was performed. Asterisks $(* * p<0.01)$ indicate a statistically significant difference.

to the baseline levels in almost all of the regions as described above, but $\mathrm{StO}_{2}$ still remained at significantly low levels, indicating a unique abnormal hemodynamic condition. Figure $9(\mathrm{~g})$ shows arterial oxygen saturation $\left(\mathrm{SpO}_{2}\right)$ measured at the hindlimb simultaneously with $\mathrm{rC}_{\mathrm{Hb}}$ and $\mathrm{StO}_{2}$ for the cortex. It should be noted that even after LISW application, $\mathrm{SpO}_{2}$ showed no significant changes at any time point, suggesting that the above-mentioned drastic changes in $\mathrm{rC}_{\mathrm{Hb}}$ and $\mathrm{StO}_{2}$ were local phenomena in the brain.

On the basis of the data of the arteriolar and venular $\mathrm{StO}_{2}$ described above, we evaluated OEF by the equation: ${ }^{33}$

$\mathrm{OEF}=1-\mathrm{StO}_{2, v} / \mathrm{StO}_{2, a}$,

where $\mathrm{StO}_{2, a}$ and $\mathrm{StO}_{2, v}$ are arteriolar and venular $\mathrm{StO}_{2}$, respectively. Mean values of $\mathrm{StO}_{2, a}$ and $\mathrm{StO}_{2, v}$ at each time point were obtained for all the RoIs described above, and OEF was then calculated for each rat. Figure 10 shows OEF values at all the six time points. The mean baseline OEF value (at $t_{0}$ ) was 0.26 , and immediately after LISW application (at $t_{1}$ ), the value increased to 0.34 . During CSD propagation (at $t_{2}$, hyperemic response to CSD), the mean OEF decreased to 0.22 , but in the post-CSD period (from $t_{3}$ to $t_{5}$ ), the value increased again and reached to the maximum of 0.40 (at $t_{4}, \sim 20 \mathrm{~min}$ post-CSD).

\section{Discussion}

Real-time observation of cerebral responses to a shock wave is crucial for understanding the pathophysiology and mechanisms of bTBI, because the initial events caused by a shock wave can trigger cascading processes leading to pathological consequences in the chronic phase. In the present study, we revealed the vascular type-dependent hemodynamic changes in the cortex from the moment of LISW application to the rat brain based on a multispectral imaging approach. In this model, we observed unique time-dependent changes in vascular diameters, $\mathrm{rC}_{\mathrm{Hb}}$, $\mathrm{StO}_{2}$, and OEF. It would be useful to analyze observed changes in the following four time regimes.
Phase I $\left(t=t_{1}\right)$ : immediately after LISW application (before the start of CSD, for $\sim 1 \mathrm{~min}$ ) in which there is immediate oligemia/hypoxemia with distinct venular constrictions,

Phase II $\left(t=t_{2}\right)$ : during CSD propagation (for $\sim 2 \mathrm{~min}$ ) in which there is a transient distinctive hyperemic response to $\mathrm{CSD}$, i.e., increases in parenchymal $\mathrm{rC}_{\mathrm{Hb}}$ and $\mathrm{StO}_{2}$ with arteriolar dilatation,

Phase III $\left(t=t_{3}\right)$ : short-term post-CSD regime (for $<20 \mathrm{~min}$ ) in which there is oligemia/hypoxemia with arteriolar constriction,

Phase IV $\left(t=t_{4} \sim t_{5}\right)$ : long-term post-CSD regime (for $>40 \mathrm{~min}$ ) in which there is long-lasting hypoxemia with neither oligemia nor arteriolar constriction but with remarkable increases in OEF (oxygen supply-demand mismatch).

The responses in phase I, i.e., direct, immediate cortical vascular and hemodynamic responses to a shock wave, are characterized by constrictions of both capillaries and venules; the parenchymal decrease in $\mathrm{rC}_{\mathrm{Hb}}$ indicates capillary constrictions. It has been reported that diameters of cerebral capillaries are controlled by pericytes ${ }^{34}$ and that capillary constriction is caused by contraction of pericytes under neuropathological conditions. ${ }^{35,36}$ It has also been shown that the active constriction of veins in acute brain injury is mostly due to contraction of pericytes. ${ }^{37}$ Thus, the immediate oligemia with venular constrictions observed in phase I is attributable to contractions of pericytes or otherwise to other contractile mural cells covering the capillaries and venules. It has been shown in a mouse ischemiareperfusion model that generation of oxygen and nitrogen radicals, e.g., peroxynitrite, caused contraction of pericytes on microvessels, resulting in capillary constriction. ${ }^{36}$ Although the type of insult is different from ours, a similar mechanism might be involved. This is because overpressure of a shock wave can increase intracellular calcium $\left(\mathrm{Ca}^{2+}\right),{ }^{38,39}$ resulting in activation of endothelial nitric oxide synthase (NOS) and hence an increase in nitric oxide (NO). ${ }^{40}$ Meanwhile, an intracellular increase in $\mathrm{Ca}^{2+}$ can stimulate the generation of reactive oxygen species (ROS) in mitochondria. ${ }^{41}$ The main ROS produced in mitochondria is known to be superoxide anion $\left(\mathrm{O}_{2}^{-*}\right)$, and $\mathrm{O}_{2}^{-*}$ and $\mathrm{NO}$ can efficiently react, producing peroxynitrite. ${ }^{42}$ We speculate that peroxynitrite is produced in the present model, leading to contraction of pericytes. In phase I, we also observed increased light scattering signals in the large venules during their constriction (Fig. 3). The venular constriction would involve cellular contractions in the vessel wall, which can result in an increase in local concentrations of macromolecules such as membrane lipid and collagenous substances, ${ }^{43-45}$ which are light scatterers. ${ }^{46}$ Thus, the scattering increase in the constricted venules would be associated with structural changes of those light scatterers.

Before starting phase II (CSD propagation), $\mathrm{rC}_{\mathrm{Hb}}$ and $\mathrm{StO}_{2}$ in the cortex had already been reduced with pial venular constriction due to the direct effects of the shock wave, as described above. Under normoxic conditions, massive hyperemia occurs in response to $\mathrm{CSD},{ }^{15,16}$ compensating the energy consumption used for restoration of imbalanced ions caused by CSD. In pathological conditions, such as mildly or moderately ischemic penumbra around a focal infarction, on the other hand, impaired cerebral blood flow $(\mathrm{CBF})$ and oxygen metabolism can transform the $\mathrm{CBF}$ response from hyperemia to a hypoperfusiondominant reaction, exacerbating tissue injury. ${ }^{15}$ The shock 
wave-induced CSD we observed showed the opposite response; distinct hyperemia occurred even under the initial hypoperfusion condition. This is probably due to the massive production of NO, which is a well-known vasodilatator, from endothelial cells by the shear force caused by the shock wave. It should also be noted that a hyperemic response to CSD was evidently observed in arterioles running in the anterograde direction to the CSD propagation direction (Fig. 4). This would be associated with the phenomenon called vascular conduction of dilatation. ${ }^{47}$ It has been demonstrated that certain vascular stimuli, e.g., local application of $\mathrm{KCl}$, induced rapid longitudinal conduction of vasomotor signals, resulting in propagation of the dilatory response. ${ }^{48}$ As one possible mechanism for the vascular conduction, electronic spread of membrane potential changes through gap junctions between vascular cells has been suggested. ${ }^{49}$

The post-CSD oligemia/hypoxemia with arteriolar constriction observed in phase III is similar to the observation in our previous study based on fiber-based DRS. In that study, postCSD hypoxemia was observed with oligemia during the whole period of measurements $(>1 \mathrm{~h}){ }^{5}$ In the present study, however, vascular constriction and oligemia recovered within $\sim 20 \mathrm{~min}$ post-CSD in phase III, but hypoxemia continued into phase IV. This difference is attributable to the different observation depths by the different methodologies and wavelengths used in the two studies: fiber-based DRS in the visible to near-infrared region (previous study) and CCD-based multispectral imaging in the visible region (present study). Observable tissue regions can be estimated as being the full thickness of the cortex (layers I-VI) in the previous study and the superficial cortical layer, i.e., mainly layer I, in the present study. ${ }^{21}$ In the rat cerebral cortex, vascular anatomy changes dramatically depending on cortical depth, e.g., capillary density increases as a function of depth, while larger-diameter arterioles and venules are dominantly located on the cortical surface. ${ }^{50,51}$ It was shown by depth-resolved laser Doppler flowmetry for rat brains that after a hyperemic response to CSD, the mean flow values for pial arterioles, venules, and other small vessels located immediately below or at the surface of the brain soon recovered to the baseline values, while the flow values at a depth of $\sim 500 \mu \mathrm{m}$ in the cortex were decreased for a while (approximately $>8 \mathrm{~min}$ ). ${ }^{52}$ Although the exact mechanisms are not clear, we assume that post-CSD persistent hypoxemia observed in the deeper cortical region results from oligemia associated with deeply located arterioles/venules and capillaries, while that observed in the superficial region is caused by the mechanisms discussed below. The hypoxemia that persisted even after recovery of blood volume with distinct venular dilatation in phase IV indicates a hypoxemic state and/or a hypermetabolic state, which seems to be unique to shock wave-related CSD responses. This can be caused by inadequate oxygen supply from blood vessels and/or excessive oxygen consumption. The mechanism for the decreased $\mathrm{StO}_{2}$ even in arterioles [Fig. 9(e), at $t_{4}$ and $t_{5}$ ] is not clear, but it may be associated with an acidic tissue condition after CSD propagation. It has been shown that extracellular lactate was increased and $\mathrm{pH}$ was decreased for more than $30 \mathrm{~min}$ after $\mathrm{KCl}$-induced CSD onset in cats. ${ }^{53}$ Such an acidic condition can also occur in the present model after CSD propagation. In addition, the hypoxemic state with restored $\mathrm{rC}_{\mathrm{Hb}}$ in this phase suggests that the tissue was supplied with glucose under the condition of insufficient oxygen delivery, accelerating lactate accumulation and hypoxemic brain acidosis. ${ }^{54}$ The lowered $\mathrm{pH}$ decreases hemoglobin affinity for oxygen as explained by the hemoglobin-oxygen dissociation curve, resulting in decreased arteriolar $\mathrm{StO}_{2}$.

Regardless of the decreased $\mathrm{StO}_{2}$ in phase IV, cellular oxygen metabolism in cortical tissue may increase in this phase, which is supported by the remarkable increases in OEF at $t_{4}$ and $t_{5}$ (Fig. 10). The initial oligemia/hypoxemia directly caused by the shock wave itself (Phase I) and the subsequent CSD (Phase II) and post-CSD hypoxemia/oligemia (Phase III) can all be regarded as a process that imposes metabolic impacts on cortical tissue. During these periods, oxidative and nitrosative stresses might have occurred successively, because CSD can be accompanied by NO production from neuronal NOS and increase in intracellular $\mathrm{Ca}^{2+},{ }^{15,16,55}$ leading to the generation of ROS. These reactions and products can increase cellular metabolism, e.g, specific protein synthesis, oxidative phosphorylation and ATP formation, ${ }^{56}$ for recovery of cellular functions, resulting in excessive oxygen consumption. Actually, OEF increased significantly in post-CSD Phase IV (at $t_{4}$ and $t_{5}$ ); the mean baseline OEF value $(0.26)$ increased to 0.40 at $\sim 20$ min post-CSD (at $\mathrm{t}_{4}$ ). It is interesting to know that a similar OEF increase has also been reported in ischemic penumbra in focal cerebral ischemia model. ${ }^{57}$ To cope with such an increased energy demand, the cortical tissue would have to struggle with energy production because capillary density is relatively low in the cortical surface region. ${ }^{50}$ From a biomechanical point of view, the cortical surface region just beneath the skull might encounter a specific type of injury resulting from cavitation because a shock wave is partly reflected at the interface between the cerebral spinal fluid and the skull. ${ }^{58}$

To validate the hypotheses for the mechanisms of hemodynamic responses to a shock wave described above, we plan to perform in vivo imaging of calcium ions and $\mathrm{NO}$, which are likely to be key players in the superacute events. Assessments of tissue $\mathrm{pH}$ and pressure characteristics just beneath the skull are also important parts of our future work. We are also currently concerned about histopathological consequences of the unique vascular and hemodynamic responses to a shock wave and the concomitant CSD observed in this study. Analyses of the related possible secondary brain damage, such as oxidative stress, blood brain barrier disruption, apoptosis, and neuroinflammation, are ongoing at present.

In summary, we here reported what we believe to be the first real-time observation of vascular type-dependent responses of hemodynamics and vessel morphology to a shock wave in the rat brain by using multispectral reflectance imaging. It was shown that hemodynamic abnormalities were caused solely by a shock wave and they were exacerbated by the occurrence of CSD. Vasoconstriction was more evident in venules than in arterioles, suggesting pericyte alteration due to a shock wave. After CSD propagation, a persistent hypoxemic state and/or hypermetabolic state (an oxygen demand-supply mismatch) was observed. These findings may give new insights into the understanding of the blast TBI mechanisms.

\section{Appendix}

The objective of this appendix is to compare the results of calculation of hemodynamic changes obtained by the multiple regression analysis described in the main text and those obtained by the conventional modified Lambert-Beer analysis. ${ }^{22,59}$ In comparison, we used the same image datasets obtained at 
(a)

Changes in
Oxy.Hb

(b)

Changes in
Deoxy. Hb

(c)

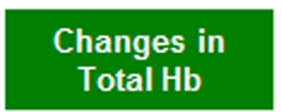

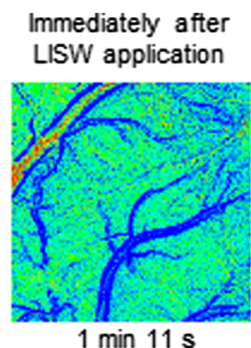
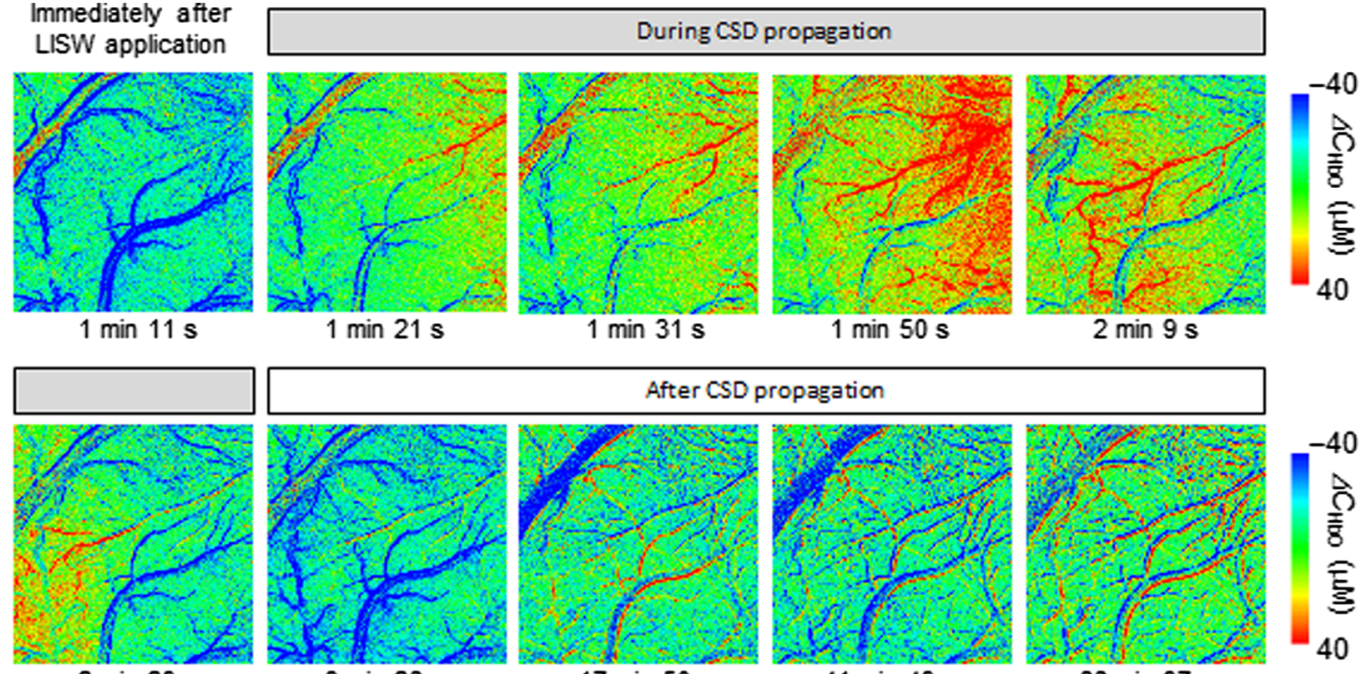

$2 \mathrm{~min} 29 \mathrm{~s}$

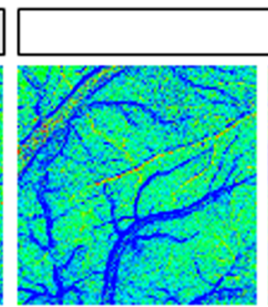

$3 \mathrm{~min} 26 \mathrm{~s}$

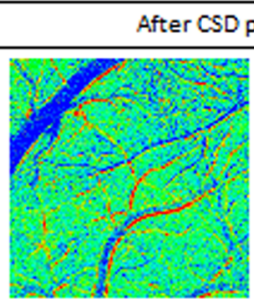

$17 \mathrm{~min} 50 \mathrm{~s}$

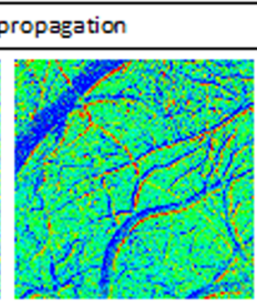

$41 \mathrm{~min} 49 \mathrm{~s}$

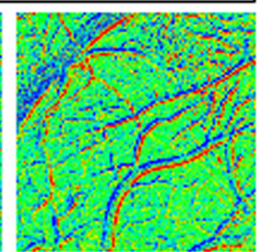

$66 \mathrm{~min} 37 \mathrm{~s}$

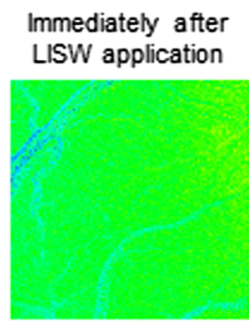

$1 \mathrm{~min} 11 \mathrm{~s}$

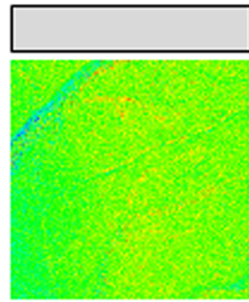

$2 \min 29 s$

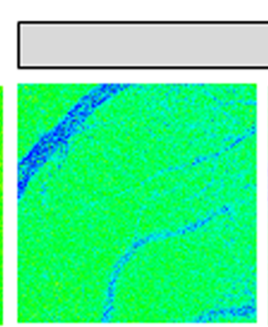

$1 \mathrm{~min} 21 \mathrm{~s}$

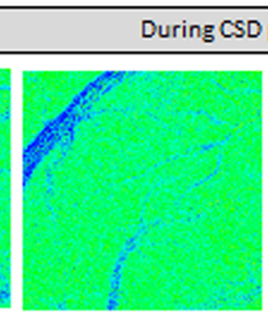

$1 \mathrm{~min} 31 \mathrm{~s}$

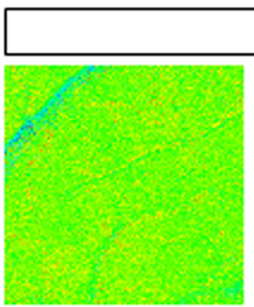

$3 \min 26 s$

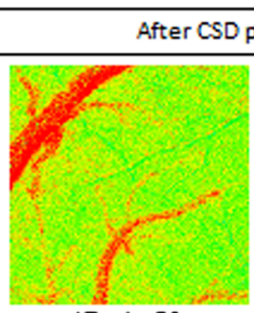

$17 \mathrm{~min} 50 \mathrm{~s}$

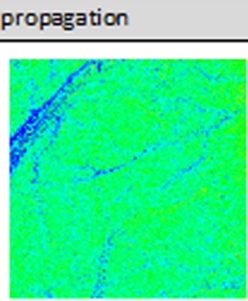

$1 \mathrm{~min} 50 \mathrm{~s}$

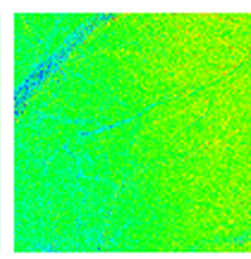

$2 \min 9 s$

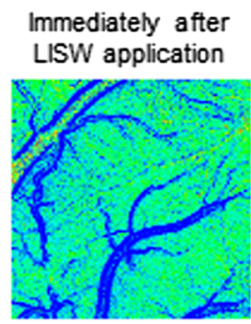

$1 \mathrm{~min} 11 \mathrm{~s}$

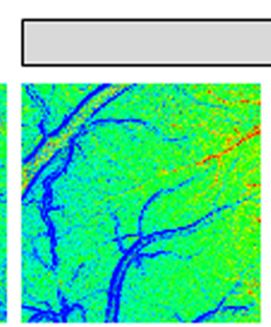

$1 \mathrm{~min} 21 \mathrm{~s}$

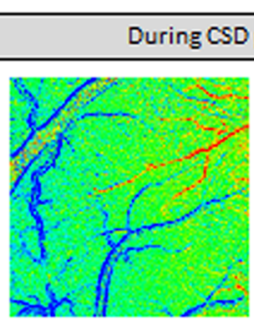

$1 \mathrm{~min} 31 \mathrm{~s}$

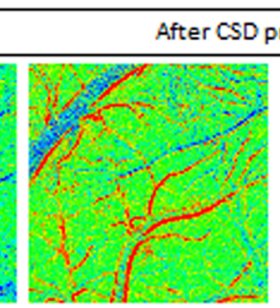

$17 \mathrm{~min} 50 \mathrm{~s}$

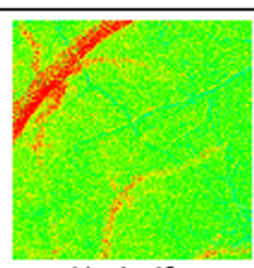

$41 \mathrm{~min} 49 \mathrm{~s}$

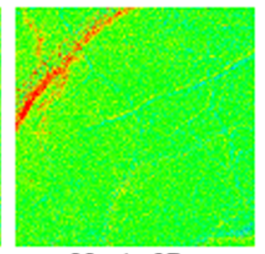

$66 \mathrm{~min} 37 \mathrm{~s}$
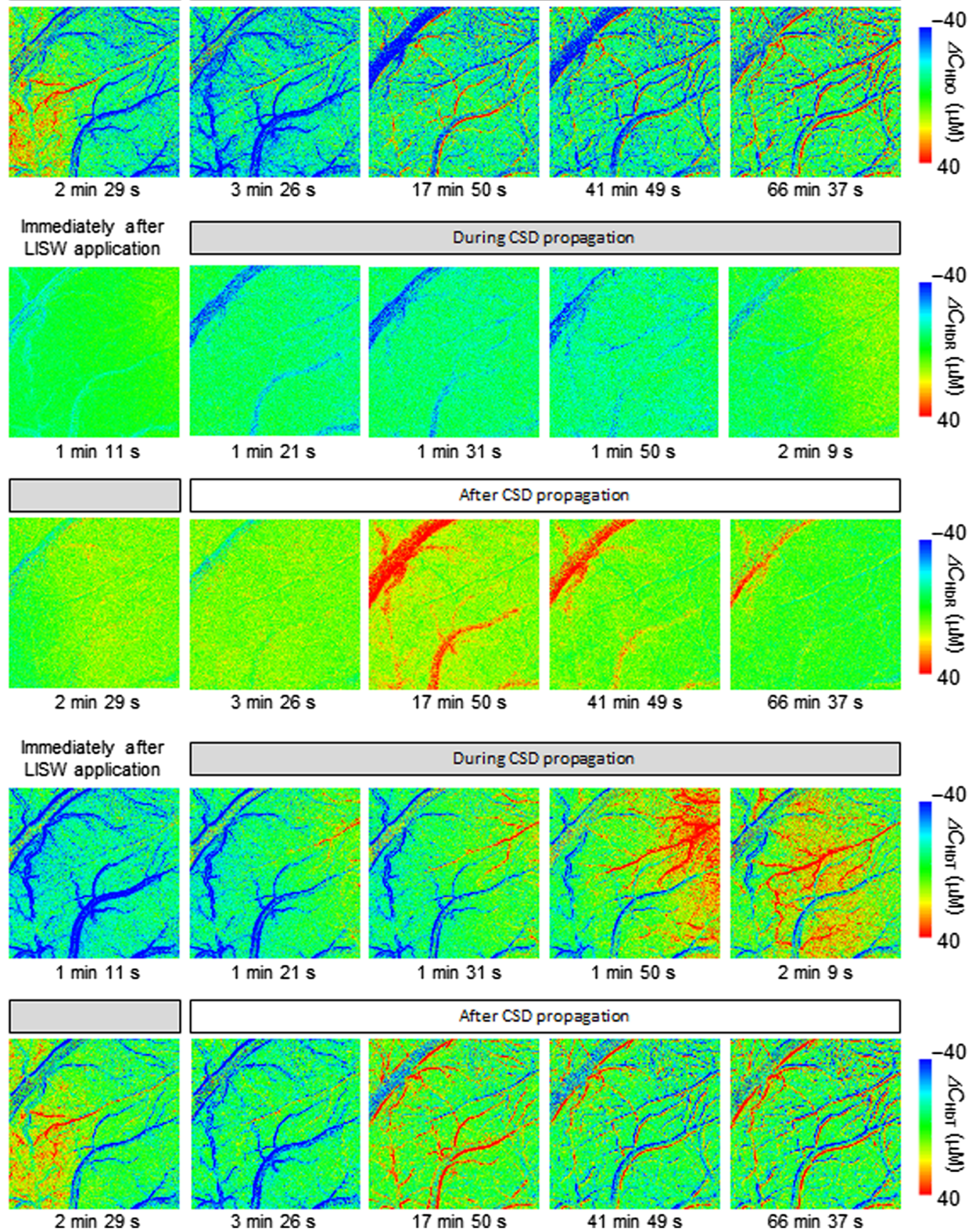

Fig. 11 Changes in concentrations of (a) oxygenated, (b) deoxygenated, and (c) total hemoglobins in the rat brain exposed to an LISW (rat no. 3) obtained by multiple regression analysis aided by Monte Carlo simulation. Each time point is the same as Fig. 7. 
(a)

Changes in
Oxy. Hb

(b)

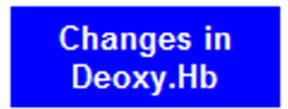

(c)

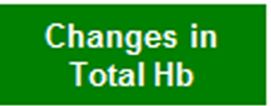

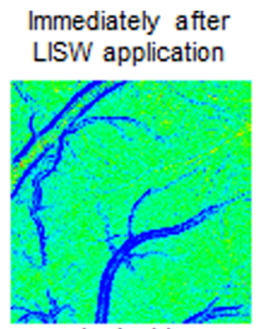

$1 \mathrm{~min} 11 \mathrm{~s}$

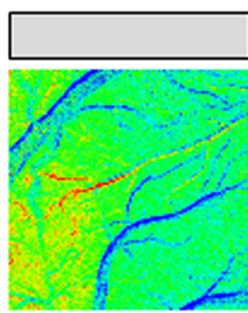

$2 \min 29 s$

Immediately after LISW application

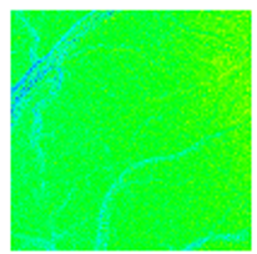

$1 \mathrm{~min} 11 \mathrm{~s}$

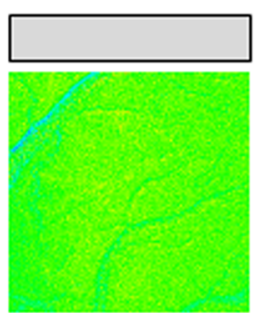

$2 \min 29 s$

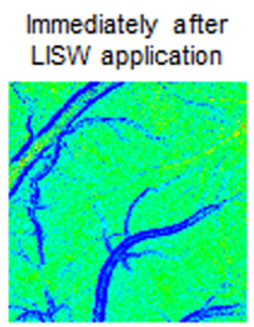

$1 \mathrm{~min} 11 \mathrm{~s}$

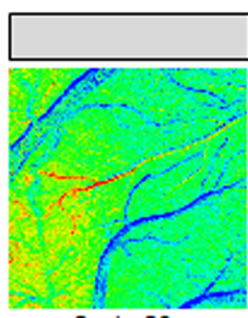

$2 \min 29 s$

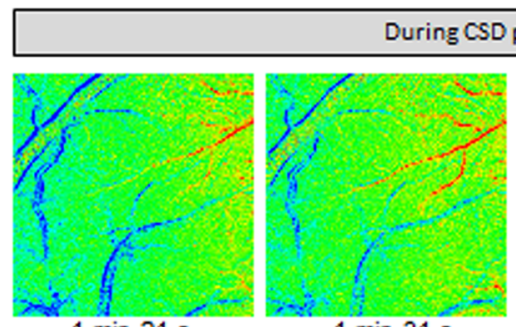

$1 \mathrm{~min} 31 \mathrm{~s}$

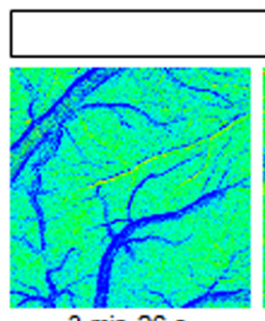

$3 \mathrm{~min} 26 \mathrm{~s}$

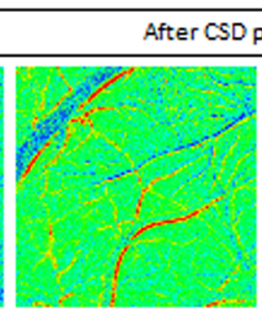

$17 \mathrm{~min} 50 \mathrm{~s}$

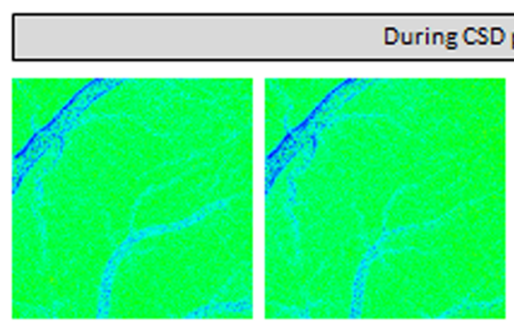

$1 \mathrm{~min} 21 \mathrm{~s}$

$1 \mathrm{~min} 31 \mathrm{~s}$
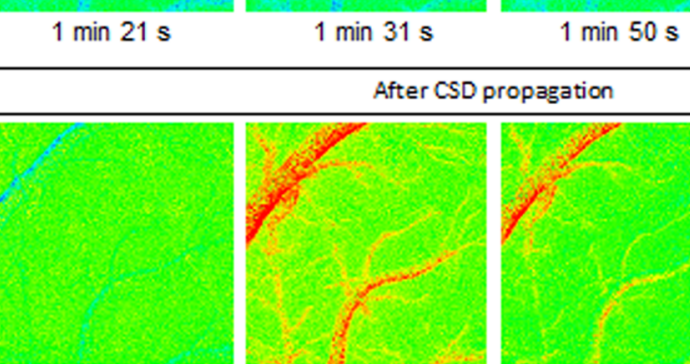

$3 \min 26 s$

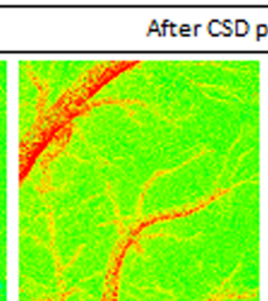

$17 \min 50 \mathrm{~s}$

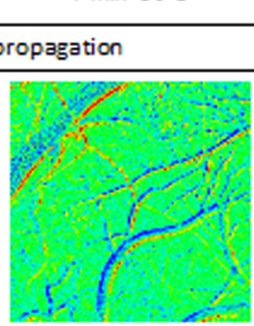

$41 \min 49 \mathrm{~s}$

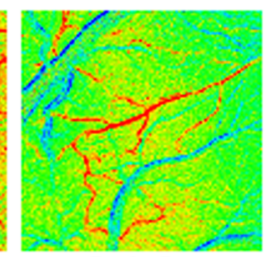

$2 \min 9 \mathrm{~s}$
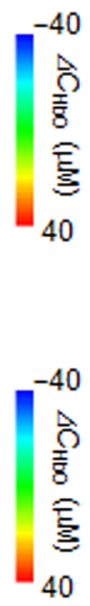

$66 \min 37 \mathrm{~s}$

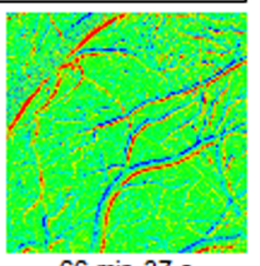

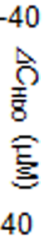

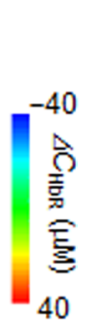

$2 \min 9 s$

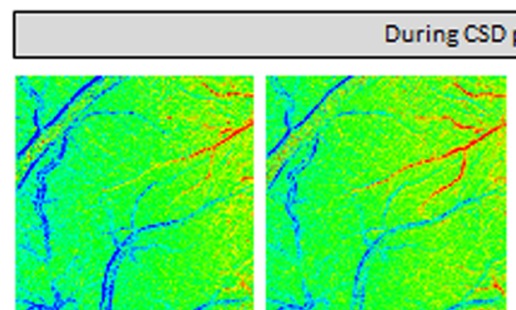

$1 \mathrm{~min} 31 \mathrm{~s}$

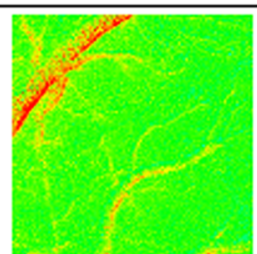

$41 \mathrm{~min} 49 \mathrm{~s}$

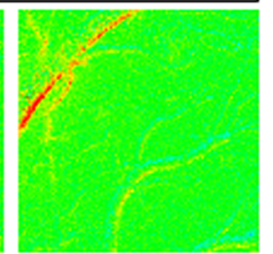

$\overbrace{40}^{-40} \frac{\hat{5}}{\text { 寒 }}$

$66 \min 37 \mathrm{~s}$

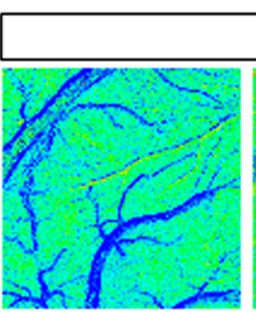

$3 \mathrm{~min} 26 \mathrm{~s}$

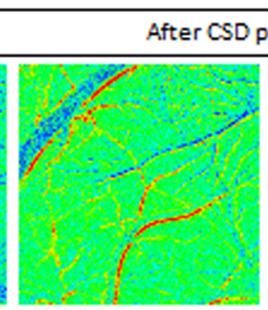

$17 \min 50 \mathrm{~s}$

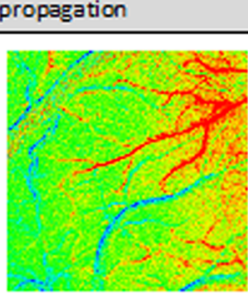

$1 \mathrm{~min} 50 \mathrm{~s}$

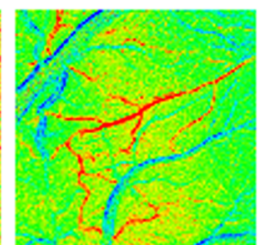

$2 \min 9 \mathrm{~s}$

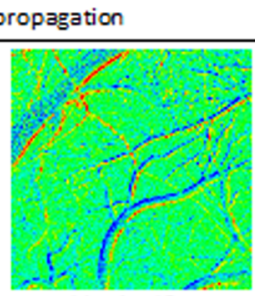

$41 \mathrm{~min} 49 \mathrm{~s}$

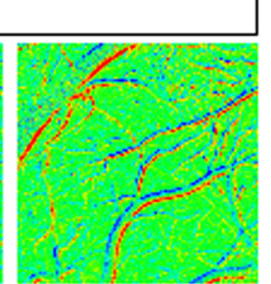

$66 \mathrm{~min} 37 \mathrm{~s}$

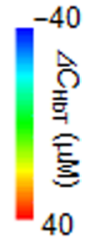

Fig. 12 Changes in concentrations of (a) oxygenated, (b) deoxygenated, and (c) total hemoglobins in the rat brain exposed to an LISW (rat no. 3) obtained by the conventional modified Lambert-Beer law. Each time point is the same as Fig. 7. 
$520,540,560,580$, and $600 \mathrm{~nm}$ for the rat brain exposed to an LISW (rat no. 3).

The modified Lambert-Beer law relates a measured reflectance intensity change to changes of chromophore concentrations. Assuming that oxygenated and deoxygenated hemoglobins are the only chromophores in the tissue of interest, the relationship between the measured reflectance intensity change and changes in $C_{\mathrm{HbO}}$ and $C_{\mathrm{HbR}}$ is described as the following equation: ${ }^{59}$

$\Delta A(\lambda)=\left\{\varepsilon_{\mathrm{HbO}}(\lambda) \Delta C_{\mathrm{HbO}}+\varepsilon_{\mathrm{HbR}}(\lambda) \Delta C_{\mathrm{HbR}}\right\} D_{a}(\lambda)$,

where $\Delta A(\lambda)=\log \left(R_{0} / R_{t}\right)$ is the attenuation at each wavelength, $R_{0}$ and $R_{t}$ are the measured reflectance intensities at time 0 (baseline) and at time $t, \Delta C_{\mathrm{HbO}}$ and $\Delta C_{\mathrm{HbR}}$ are concentration changes of $\mathrm{HbO}$ and $\mathrm{HbR}$, respectively, and $\varepsilon_{\mathrm{HbO}}$ and $\varepsilon_{\mathrm{HbR}}$ are the respective molar extinction coefficients. Equation (10) can be solved for $\Delta C_{\mathrm{HbO}}$ and $\Delta C_{\mathrm{HbR}}$ using a least-square approach. The differential pathlength factor, $D_{a}(\lambda)$, accounts for the fact that a photon at each wavelength travels a slightly different optical path through the tissue due to the wavelength-dependent scattering and absorption coefficients in the tissue, and it can be estimated using the approach developed by Kohl et al. ${ }^{22}$ on the basis of MCS of light propagation in a homogeneous tissue model. The wavelength-dependent reflectance, $R\left[\mu_{a}(\lambda)\right.$ ], can also be calculated using MCS to determine $D_{a}(\lambda){ }^{22}$ In the analysis here, the baseline reduced scattering coefficient, $\mu_{\mathrm{s}}^{\prime}$ was assumed to be 12 to $16 \mathrm{~cm}^{-1}$ at $520,540,560,580$, and $600 \mathrm{~nm}^{26}$ and was assumed to be constant with time according to the literature. ${ }^{22,59}$

Figures 11 and 12 show images of the changes in $C_{\mathrm{HbO}}$, $C_{\mathrm{HbR}}$, and $C_{\mathrm{HbT}}$ obtained by the multiple regression analysis and the conventional modified Lambert-Beer analysis, respectively (rat no. 3). Time courses of changes in $C_{\mathrm{HbO}}, C_{\mathrm{HbR}}$, and $C_{\mathrm{HbT}}$ shown in Fig. 11 are consistent with the time-dependent changes in regional hemoglobin concentration $\left(\mathrm{rC}_{\mathrm{Hb}}\right)$ and tissue oxygen saturation $\left(\mathrm{StO}_{2}\right)$ shown in Fig. 7. It should be noted, however, that some regions at the vessel edges show extremely high or low values, which is attributable to changes in these vessels' diameters. Figure 12 shows the corresponding results obtained by the conventional modified Lambert-Beer analysis. The tendencies similar to those in Fig. 11 can be seen in Fig. 12. However, the values of changes in Fig. 12 are slightly smaller than those in Fig. 11. This may be due to the different assumption regarding the scattering coefficient; in the modified Lambert-Beer law analysis, the scattering coefficient was treated as constant. The authors plan to conduct more comprehensive comparison between the two methods.

\section{Disclosure}

The authors have no conflicts of interests related to this work.

\section{Acknowledgments}

The authors gratefully acknowledge the financial support of the Ministry of Defense Research Program for Advanced Defense Medicine and US-ARMY ITC-PAC Research and Development Project (FA5209-15-P-0175 and FA5209-16-P-0132). We thank A. Kamoshida for technical support in the use of image acquisition and processing software (LabVIEW) and H. Inose, Y. Muramatsu, and A. Kono for technical assistance in data analysis and histopathological assessments. The present study was performed in a doctoral program of Graduate School of
Bio-Applications \& Systems Engineering, Tokyo University of Agriculture and Technology.

\section{References}

1. Y. Bogdanova and M. Verfaellie, "Cognitive sequelae of blast-induced traumatic brain injury: recovery and rehabilitation," Neuropsychol. Rev. 22(1), 4-20 (2012).

2. C. W. Hoge et al., "Mild traumatic brain injury in U.S. Soldiers returning from Iraq," N. Engl. J. Med. 358(5), 453-463 (2008).

3. J. V. Rosenfeld et al., "Blast-related traumatic brain injury," Lancet Neurol. 12(9), 882-893 (2013).

4. S. B. Shively and D. P. Perl, "Traumatic brain injury, shell shock, and posttraumatic stress disorder in the military-past, present, and future," J. Head Trauma Rehabil. 27(3), 234-239 (2012).

5. S. Sato et al., "Real-time optical diagnosis of the rat brain exposed to a laser-induced shock wave: observation of spreading depolarization, vasoconstriction and hypoxemia-oligemia," PLoS One 9(1), e82891 (2014).

6. Y. Satoh et al., "Pulmonary blast injury in mice: a novel model for studying blast injury in the laboratory using laser-induced stress waves," Lasers Surg. Med. 42(4), 313-318 (2010).

7. T. Kurioka et al., "Characteristics of laser-induced shock wave injury to the inner ear of rats," J Biomed. Opt. 19(12), 125001 (2014).

8. K. Niwa et al., "Pathophysiology of the inner ear after blast injury caused by laser-induced shock wave," Sci. Rep. 6, 31754 (2016).

9. H. Miyazaki et al., "Thoracic shock wave injury causes behavioral abnormalities in mice," Acta Neurochir. (Wien) 157(12), 2111-2120 (2015).

10. S. Takeuchi et al., "A better mild traumatic brain injury model in the rat," Acta Neurochir. Suppl. 118, 99-101 (2013).

11. D. V. Agoston and A. Kamnaksh, "Modeling the neurobehavioral consequences of blast-induced traumatic brain injury spectrum disorder and identifying related biomarkers," Chapter 23, in Brain Neurotrauma, F. H. Kobeissy, Ed., CRC Press/Taylor \& Francis, Boca Raton, Florida (2015).

12. R. H. Garman et al., "Blast exposure in rats with body shielding is characterized primarily by diffuse axonal injury," J. Neurotrauma 28(6), 947-959 (2011).

13. M. Risling and J. Davidsson, "Experimental animal models for studies on the mechanisms of blast-induced neurotrauma," Front. Neurol. 3, 30 (2012).

14. W. Okuda et al., "Optical monitoring of shock wave-induced spreading depolarization and concomitant hypoxemia in rat brain," Proc. SPIE 8928, 892829 (2014).

15. C. Ayata and M. Lauritzen, "Spreading depression, spreading depolarizations, and the cerebral vasculature," Physiol. Rev. 95(3), 953-993 (2015).

16. J. P. Dreier, "The role of spreading depression, spreading depolarization and spreading ischemia in neurological disease," Nat. Med. 17(4), 439447 (2011).

17. A. A. P. Leao, "Spreading depression of activity in cerebral cortex," J. Neurophysiol. 7, 359-390 (1944).

18. I. Nishidate et al., "Evaluation of cerebral hemodynamics and tissue morphology of in vivo rat brain using spectral diffuse reflectance imaging," Appl. Spectrosc. 71(5), 866-878 (2017).

19. K. Yoshida et al., "Multispectral imaging of absorption and scattering properties of in vivo exposed rat brain using a digital red-green-blue camera," J. Biomed. Opt. 20(5), 051026 (2015).

20. M. D. Alley, "Explosive blast loading experiments for TBI scenarios: characterization and mitigation," MSME Thesis, Purdue University, ProQuest LLC, Ann Arbor, Michigan (2009).

21. S. Kawauchi et al., "Diffuse light reflectance signals as potential indicators of loss of viability in brain tissue due to hypoxia: charge-coupleddevice-based imaging and fiber-based measurement," J. Biomed. Opt. 18(1), 015003 (2013).

22. M. Kohl et al., "Physical model for the spectroscopic analysis of cortical intrinsic optical signals," Phys. Med. Biol. 45(12), 3749-3764 (2000).

23. P. B. Jones et al., "Simultaneous multispectral reflectance imaging and laser speckle flowmetry of cerebral blood flow and oxygen metabolism in focal cerebral ischemia," J. Biomed. Opt. 13(4), 044007 (2008). 
24. J. R. Mourant et al., "Mechanisms of light scattering from biological cells relevant to noninvasive optical-tissue diagnostics," Appl. Opt. 37(16), 3586-3593 (1998).

25. D. Abookasis et al., "Imaging cortical absorption, scattering, and hemodynamic response during ischemic stroke using spatially modulated near-infrared illumination," J. Biomed. Opt. 14(2), 024033 (2009).

26. V. Tuchin, Tissue Optics: Light Scattering Methods and Instruments for Medical Diagnosis, 2nd ed., SPIE Press, Bellingham, Washington (2007).

27. L. Wang, S. L. Jacques, and L. Zheng, "MCML-Monte Carlo modeling of light transport in multi-layered tissues," Comput. Methods Programs Biomed. 47(2), 131-146 (1995).

28. S. A. Prahl, "Tabulated molar extinction coefficient for hemoglobin in water," 1999, https://omlc.org/spectra/hemoglobin/summary.html

29. D. X. Hammer et al., "Longitudinal vascular dynamics following cranial window and electrode implantation measured with speckle variance optical coherence angiography," Biomed. Opt. Express 5(8), 28232836 (2014).

30. E. Gutiérrez-Jiménez et al., "Disturbances in the control of capillary flow in an aged APPswe/PS1 $\triangle E$ E model of Alzheimer's disease," Neurobiol. Aging 62, 82-94 (2018).

31. M. Schueler et al., "Innervation of rat and human dura mater and pericranial tissues in the parieto-temporal region by meningeal afferents," Headache 54(6), 996-1009 (2014).

32. G. G. Somjen, "Mechanisms of spreading depression and hypoxic spreading depression-like depolarization," Physiol. Rev. 81(3), 10651096 (2001).

33. M. Dehaes et al., "Perioperative cerebral hemodynamics and oxygen metabolism in neonates with single-ventricle physiology," Biomed. Opt. Express 6(12), 4749-4767 (2015).

34. C. M. Peppiatt et al., "Bidirectional control of CNS capillary diameter by pericytes," Nature 443(7112), 700-704 (2006).

35. N. B. Hamilton, D. Attwell, and C. N. Hall, "Pericyte-mediated regulation of capillary diameter: a component of neurovascular coupling in health and disease," Front. Neuroenerget. 2, 5 (2010).

36. M. Yemisci et al., "Pericyte contraction induced by oxidative-nitrative stress impairs capillary reflow despite successful opening of an occluded cerebral artery," Nat. Med. 15(9), 1031-1037 (2009).

37. S. Chen et al., "Venous system in acute brain injury: mechanisms of pathophysiological change and function," Exp. Neurol. 272, 4-10 (2015).

38. R. Ravin et al., "Blast shockwaves propagate $\mathrm{Ca}^{2+}$ activity via purinergic astrocyte networks in human central nervous system cells," Sci. Rep. 6, 25713 (2016).

39. R. Ravin et al., "Shear forces during blast, not abrupt changes in pressure alone, generate calcium activity in human brain cells," PLoS One 7(6), e39421 (2012).

40. J. L. Balligand, O. Feron, and C. Dessy, "eNOS activation by physical forces: from short-term regulation of contraction to chronic remodeling of cardiovascular tissues," Physiol. Rev. 89(2), 481-534 (2009).

41. P. S. Brookes et al., "Calcium, ATP, and ROS: a mitochondrial love-hate triangle," Am. J. Physiol. Cell Physiol. 287(4), C817-C833 (2004).

42. P. Pacher, J. S. Beckman, and L. Liaudet, "Nitric oxide and peroxynitrite in health and disease," Physiol. Rev. 87(1), 315-424 (2007).

43. P. G. Aitken et al., "Use of intrinsic optical signals to monitor physiological changes in brain tissue slices," Methods 18(2), 91-103 (1999).

44. R. D. Andrew, C. R. Jarvis, and A. S. Obeidat, "Potential sources of intrinsic optical signals imaged in live brain slices," Methods 18(2), 185-196 (1999)

45. L. Edvinsson et al., "Cerebral veins: fluorescence histochemistry, electron microscopy, and in vitro reactivity," J. Cereb. Blood Flow Metab. 3(2), 226-230 (1983).

46. J. R. Mourant and I. J. Bigio, "Elastic-scattering spectroscopy and diffuse reflectance," Chapter 29 in Biomedical Photonics Handbook, T. Vo-Dinh, Ed., CRC Press, Boca Raton, Florida (2003).

47. C. de Wit, B. Hoepfl, and S. E. Wölfle, "Endothelial mediators and communication through vascular gap junctions," Biol. Chem. 387(1), 3-9 (2006).

48. T. Horiuchi et al., "Mechanism of extracellular K+-induced local and conducted responses in cerebral penetrating arterioles," Stroke 33(11), 2692-2699 (2002).
49. K. C. Brennan et al., "Distinct vascular conduction with cortical spreading depression," J. Neurophysiol. 97(6), 4143-4151 (2007).

50. M. J. Cipolla, "The cerebral circulation, second edition," in Colloquium Series on Integrated Systems Physiology: From Molecule to Function to Disease, D. N. Granger and J. P. Granger, Eds., Morgan \& Claypool Life Sciences, San Rafael, California (2006).

51. P. S. Tsai et al., "Correlations of neuronal and microvascular densities in murine cortex revealed by direct counting and colocalization of nuclei and vessels," J. Neurosci. 29(46), 14553-14570, (2009).

52. A. N. Nielsen, M. Fabricius, and M. Lauritzen, "Scanning laser-Doppler flowmetry of rat cerebral circulation during cortical spreading depression," J. Vasc. Res. 37(6), 513-522 (2000).

53. P. Hashemi et al., "Persisting depletion of brain glucose following cortical spreading depression, despite apparent hyperaemia: evidence for risk of an adverse effect of Leão's spreading depression," J. Cereb. Blood Flow Metab. 29(1), 166-175 (2009).

54. S. Rehncrona, "Brain acidosis," Ann. Emerg. Med. 14(8), 770-776 (1985).

55. D. W. Busija et al., "Mechanisms involved in the cerebrovascular dilator effects of cortical spreading depression," Prog. Neurobiol. 86(4), 417-433 (2008)

56. G. Marchal, A. R. Young, and J. C. Baron, "Early postischemic hyperperfusion: pathophysiologic insights from positron emission tomography," J. Cereb. Blood Flow Metab. 19(5), 467-482 (1999).

57. F. Y. Chang et al., "Determination of oxygen extraction fraction using magnetic resonance imaging in canine models with internal carotid artery occlusion," Sci. Rep. 6, 30332 (2016).

58. A. Nakagawa et al., "Mechanisms of primary blast-induced traumatic brain injury: insights from shock-wave research," J. Neurotrauma 28(6), 1101-1119 (2011).

59. A. K. Dunn et al., "Spatial extent of oxygen metabolism and hemodynamic changes during functional activation of the rat somatosensory cortex," Neuroimage 27(2), 279-290 (2005).

Satoko Kawauchi is a lecturer at National Defense Medical College Research Institute. She received her BS and MS degrees in electrical engineering from Keio University (Japan) in 1996 and 1998, respectively, and her PhD in medical science from the School of Medicine, Kyorin University (Japan), in 2005. Her interests cover laser-tissue interactions, particularly PDT, LLLT, diffuse reflectance spectroscopy, and photoacoustic imaging. Neurophotonics is a recent important research field.

Wataru Okuda received his BS and MS degrees from the Graduate School of Bio-Applications and Systems Engineering, Tokyo University of Agriculture and Technology. His research interests include diffuse reflectance spectroscopy and multispectral imaging of brain tissues.

Hiroshi Nawashiro received his PhD from the National Defense Medical College (NDMC), Japan. He was a guest researcher at the National Institute of Neurological Disorders and Stroke (NINDS) in the US National Institutes of Health (NIH) and was an associate professor at NDMC. He is a deputy chief of Tokorozawa Central Hospital, Japan. His research interests cover traumatic brain injury and photobiomodulation therapy for patients with brain dysfunction.

Shunichi Sato received his $\mathrm{MS}$ and $\mathrm{PhD}$ degrees from Keio University, Japan. He is a professor at the Division of Bioinformation and Therapeutic Systems, National Defense Medical College Research Institute, Japan. His research interests include photomechanical waves and their application to gene/drag delivery systems, photoacoustic imaging, photodynamic therapy, and diagnosing/imaging brain tissue viability.

Izumi Nishidate received his MS and PhD degrees from Muroran Institute of Technology, Japan. He is an associate professor at the Graduate School of Bio-Applications and Systems Engineering, Tokyo University of Agriculture and Technology. His research interests include diffuse reflectance spectroscopy, light transport in biological tissues, multispectral imaging, and functional imaging of skin and brain tissues. 